\title{
Insights into homeobox B9: a propeller for metastasis in dormant prostate cancer progenitor cells
}

\author{
Yi Sui ${ }^{1,8}$, Wei Hu ${ }^{2,8}$, Wei Zhang ${ }^{3,8}$, Dejian $\mathrm{Li}^{4}$, Hongbo Zhu ${ }^{5}$, Qinghua You ${ }^{5}$, Rujian Zhu ${ }^{2}$, Qingtong Yi $^{2}$, Tao Tang ${ }^{6}$, Lili Gao ${ }^{7}$, \\ Shengjuan $\mathrm{Zhu}^{7}$ and Tao Yang ${ }^{7 凶}{ }^{7 凶}$
}

(c) The Author(s) 2021

BACKGROUND: Metastasis is the major cause of treatment failure and cancer-related deaths in prostate cancer (PCa) patients. Our previous study demonstrated that a $\mathrm{CD}_{4} 4^{+}$subpopulation isolated from PCa cells or tumours possesses both stem cell properties and metastatic potential, serving as metastatic prostate cancer stem cells (mPCSCs) in PCa metastasis. However, the underlying mechanisms remain unknown.

METHODS: In this study, we established PCa models via the orthotopic and subcutaneous implantation of different human PCa cancer cell lines, and compared the metastatic efficacy, after which process function analysis of target genes was pinpointed. RESULTS: Several novel differentially expressed genes (DEGs) between orthotopic and ectopic tumours were identified. Among them, human homeobox B9 (HOXB9) transcription factor was found to be essential for PCa metastasis, as evidenced by the diminished number of lung metastatic foci derived from orthotopic implantation with HOXB9-deficient CWR22 cells, compared with the control. In addition, HOXB9 protein expression was upregulated in PCa tissues, compared with paracancer and benign prostate hyperplasia tissues. It was also positively correlated with Gleason scores. Gain- and loss-of-function assays showed that HOXB9 altered the expression of various tumour metastasis- and cancer stem cell (CSC) growth-related genes in a transforming growth factor beta (TGF $\beta$ )-dependent manner. Moreover, HOXB9 was overexpressed in an $\mathrm{ALDH}^{+} \mathrm{CD} 44^{+} \mathrm{CXCR} 4^{+} \mathrm{CD} 24^{+}$subpopulation of PCa cells that exhibited enhanced TGF $\beta$-dependent tumorigenic and metastatic abilities, compared with other isogenic PCa cells. This suggests that HOXB9 may contribute to PCa tumorigenesis and metastasis via TGF $\beta$ signalling. Of note, $\mathrm{ALDH}^{+} \mathrm{CD} 44^{+} \mathrm{CXCR} 4^{+} \mathrm{CD} 24^{+}-\mathrm{PCa}$ cells exhibited resistance to castration and antiandrogen therapy and were present in human PCa tissues.

CONCLUSION: Taken together, our study identified HOXB9 as a critical regulator of metastatic mPCSC behaviour. This occurs through altering the expression of a panel of CSC growth- and invasion/metastasis-related genes via TGF $\beta$ signalling. Thus, targeting HOXB9 is a potential novel therapeutic PCa treatment strategy.

British Journal of Cancer (2021) 125:1003-1015; https://doi.org/10.1038/s41416-021-01482-y

\section{INTRODUCTION}

Prostate cancer (PCa) is the third most common cancer and the sixth leading cause of cancer-related death among males worldwide [1]. PCa incidence varies throughout the world, with the highest rates in western countries and the lowest in South Asia [2]. Although patients with localised and regional PCa are curable with a 5-year survival rate of $\sim 100 \%$ upon diagnosis, those with distant metastases have a 5-year survival of only $29 \%$ [3]. Therefore, elucidation of the mechanisms underlying PCa progression and metastasis is required to improve the disease's treatment efficacy and prognosis.

Metastasis is a complex multistep process that involves the migration of tumour cells from the primary tumour, and the subsequent initiation of secondary tumours in distant organs [4]. It is well known that metastasis is an inefficient process, as only about $0.2 \%$ of disseminated tumour cells form metastases in distant organs [5]. Metastatic cancer stem cells (CSCs), which comprise a small subgroup of CSCs with both stem cell properties and metastatic potentials, are believed to be metastatic precursors that drive tumour invasion and metastasis [6]. There is a close association between CSC markers and cell phenotypes. CD44 [7], CD24 [8], CD133 [9], aldehyde dehydrogenase (ALDH) [10], integrin $\alpha 2 \beta 1$ [11] and C-X-C chemokine receptor type 4 (CXCR4) [12] are well-accepted CSCs markers in PCa. CD44 ${ }^{+}$PCa cells are more proliferative, clonogenic, tumorigenic, and metastatic than the isogenic CD44 ${ }^{-}$PCa cells [13]. A Higher CD44 ${ }^{+}$population was

\footnotetext{
${ }^{1}$ Department of Nutrition, The First Affiliated Hospital of Sun Yat-sen University, Guangzhou, China. ${ }^{2}$ Department of Urology, Shanghai Pudong Hospital, Fudan University Pudong Medical Center, Shanghai, China. ${ }^{3}$ Department of Pharmacology, School of Basic Medicine, Hebei University of Chinese Medicine, Shijiazhuang, China. ${ }^{4}$ Department of Othopedics, Shanghai Pudong Hospital, Fudan University Pudong Medical Center, Shanghai, China. ${ }^{5}$ Department of Pathology, Shanghai Pudong Hospital, Fudan University Pudong Medical Center, Shanghai, China. ${ }^{6}$ Department of Obstetrics and Gynaecology, Prince of Wales Hospital, The Chinese University of Hong Kong, Hong Kong SAR, China. ${ }^{7}$ Center for Medical Research and Innovation, Shanghai Pudong Hospital, Fudan University Pudong Medical Center, Shanghai, China. ${ }^{8}$ These authors contributed equally: Yi Sui, Wei Hu, Wei Zhang. ${ }^{凶}$ email: yangt@fudan.edu.cn
} 
showed in Docetaxel-resistant PCa cells and promotes migration and invasion probably via induction of Hippo-Yap signialing pathway [14]. This suggests that $\mathrm{CD}_{4}{ }^{+}$subpopulations may act as metastatic prostate CSCs (mPCSCs). CD24 is a significant predictor for PCa relapse and poor prognosis [15]. Circulating tumour cells (CTCS) from patients with metastatic castration-resistant prostate cancer (mCRPC) have robust CD133 protein expression and high levels of CD133 are associated with increased capacity for proliferation [16]. High ALDH activity can be used to identify tumour initiating and metastasis initiating cells in PCa [17]. Integrin a2 $\beta 1$ is needed for the efficient metastasis of PCa cells to the skeleton [18]. PCa and perhaps other neoplasms (e.g., breast) may use the chemokine stromal cell-derived factor-1 (SDF-1 or CXCL1) and its receptor CXCR4 to promote their spreading to the bone and other tissues $[19,20]$. Similarly, CD133 ${ }^{+}$CXCR4 ${ }^{+}$cells, but not $\mathrm{CD} 133^{+} \mathrm{CXCR}^{-}$cells, are essential for pancreatic tumour metastasis [21]. Furthermore, $\mathrm{CD} 44^{+} \mathrm{CD} 24^{- \text {low }}$ breast cancer CSCs isolated from both primary tumours and lung metastatic foci can generate orthotopic primary tumours and subsequent lung metastases [22]. This provides the most direct evidence of the presence of metastatic CSCs and for the CSCs' contribution to metastasis. Although the link between genetic signatures and $\mathrm{CSCs}^{\prime}$ metastatic potential has been established, the regulatory mechanisms remain unclear.

It has been established that the orthotopic implantation of cancer in nude mice produces distant metastases, whereas subcutaneous transplantation does not $[23,24]$. This indicates the importance of tumour microenvironments in metastasis. The differential gene expression profiles of orthotopic and ectopic tumour implantation models may provide clues to understanding metastatic mechanisms. In this study, we compare the metastatic rates of tumour models established via orthotopic and subcutaneous implantation using different human PCa cell lines. To do so, PCa cell lines with the highest metastatic rate were selected for further analysis of the differentially expressed genes (DEGs) in orthotopic and ectopic tumours. The findings show that human homeobox B9 (HOXB9), a key transcription factor that promotes metastases in lung and breast cancers $[25,26]$, is involved in enhanced metastatic capacity and resistance to physical/chemical castration therapy in the PCa model caused by orthotopic implantation of $\mathrm{ALDH}^{+} \mathrm{CD} 44^{+} \mathrm{CXCR} 4^{+} \mathrm{CD} 24^{+}$ subpopulation. Our study reveals that HOXB9 can regulate the expression of a panel of CSC growth- and invasion/metastasisrelated genes in $\mathrm{mPCSC}$ s via TGF $\beta$ signalling. This suggests that HOXB9 is a novel therapeutic target in PCa treatment.

\section{MATERIALS AND METHODS \\ Patients and tissue samples}

Para-carcinoma and PCa tissues were obtained from 32 patients with primary PCa who had undergone radical prostatectomy at the Department of Urology, Fudan University Pudong Medical Center, between January 1998 and July 2018, for patient-derived xenograft (PDX) study, as well as tumour cell phenotyping and in vivo inoculation assay. Benign prostate hyperplasia tissues were obtained from diagnostic prostate needle biopsies. All tissue samples were processed immediately after surgical removal. Diagnosis and grading were histologically confirmed by two experienced pathologists, according to the Gleason grading system. The tumour tissues were fixed in 10\% formalin, embedded in paraffin and cut into 4-7- $\mu \mathrm{m}$ thick sections. For correlation analysis in terms of HOXB9 expression level, Gleason scores and prognostic features, patients data and tissue samples ( $n=12$; starting from January 1998 until October 2015) were retrieved from the Department of Health Information in Fudan University Pudong Medical Center. This study was approved by the Ethics Committee of Fudan University Pudong Medical Center, as well as local authorities. Written consent was obtained from all patients.

\section{Animals}

Six- to eight-week-old male NOD/SCID mice weighing 22-25 g were produced from our own breeding colonies or purchased from Jackson
Laboratories (Bar Harbor, ME, USA). They were maintained in standard conditions according to institutional guidelines. All animal care and procedures described in this study were approved by the Ethics Committee of Shanghai Pudong Hospital (Shanghai, China). All animal experiments were performed in accordance with the guidelines for the proper conduct of animal experiments, as stipulated by Shanghai Pudong Hospital and Fudan University (Shanghai, China).

\section{Cell culture}

PCa cells (CWR22, Du-145, LNCaP, LAPC4 or LAPC9) were obtained from American Type Culture Collection (ATCC, Manassas, VA, USA). CWR22, Du145 and LNCaP were cultured in RPMI- 1640 plus $8 \%$ heat-inactivated foetal bovine serum (FBS); whereas LAPC4 and LAPC9 were maintained in NOD/ SCID male mice. CWR22, Du-145 or LNCaP cells overexpressing GFP or RFP, and CWR22 cells overexpressing luciferase (Luc-CWR22) were cultured, as previously described $[27,28]$, and maintained in RPMI- 1640 supplemented with $8 \% \mathrm{FBS}$ at $37^{\circ} \mathrm{C}$ in a humidified atmosphere of $5 \% \mathrm{CO}_{2}$.

\section{Tumour models comparing orthotopic and ectopic implantation}

Mice were randomly separated into different groups ( $n=12 /$ group). Animals were anaesthetised with inhalation of $3 \%$ halothane and maintained on $1.5 \%$ halothane in $70 \%$ nitrous oxide and $30 \%$ oxygen. In total, $1 \times 10^{5}$ PCa cells (CWR22, Du-145, LNCaP, LAPC4 or LAPC9) were injected into the dorsal lobe of the prostate or subcutaneous area of the same mouse. After that, mice were placed at $37^{\circ} \mathrm{C}$ and monitored in microisolator cages (one per cage) until they recovered from surgery. Mice were sacrificed by $\mathrm{CO}_{2}$ asphyxiation at 2 months after the initial appearance of tumours, and the primary tumours were immediately harvested, weighed, and stored at $-80^{\circ} \mathrm{C}$ until use. GFP- or RFP-expressing primary tumours and metastases in miscellaneous organs (bilateral lungs and kidneys, pancreas, liver, spleen, brain and bone marrow) were visualised, and representative images were acquired using Nikon SMZ1500 whole-mount epifluorescence dissecting microscopy (Nikon, Japan). The metastasis rate was calculated as the number of metastatic foci detected in each group/(the number of detected organs $\times$ the number of mice in each group).

\section{Microarray analysis}

The gene expression profile of each sample was examined using an Affymetrics Genechip (ThermoFisher Scientific, Waltham, MA, USA) containing probes covering 8500 protein-coding genes following the manufacturer's standard protocols. The DEGs between each group were screened using a random variance model (RVM) $t$ test. Genes for expression levels with $P$ value $<0.05$ and fold change $>2$ were considered to be DEGs. Cluster analysis was performed using hierarchical clustering.

\section{Immunofluorescence staining}

The tissue sections were subject to HOXB9 immunostaining according to the standard protocol [29]. Sections were incubated with mouse antihuman HOXB9 antibody (Millipore, Billerica, MA, USA). Sections were further incubated with tetramethylrhodamine isothiocyanate (TRITC)conjugated goat anti-mouse IgG (1:100, Millipore). Rinsed sections were counterstained with $10 \mu \mathrm{g} / \mathrm{ml}$ 4',6-diamidino-2-phenylindole (DAPI, Sigma, St. Louis, MO, USA). Normal lgG was used as a negative control. An inverted fluorescence microscope (IX83, Olympus, Tokyo, Japan) was used for visualisation, and red staining was considered HOXB9-positive.

\section{CSC growth-related DEG knockdown in CWR22-GFP cells and the establishment of an orthotopic tumour model}

The vectors expressing shRNAs of 12 CSC growth-related genes (Supplementary Table 1), such as CXCR4 (C-X-C chemokine receptor type 4), CD133 (Prominin-1), ABCG2 (ATP-binding cassette subfamily G member 2), CD24 (signal transducer CD24), HOXB9 (homeobox protein Hox-B9), NOS2A (inducible nitric oxide synthase), TROP2 (tumour-associated calcium signal transducer 2), LRIG1 (leucine-rich repeats and immunoglobulin-like domains protein 1), WNT4 (wingless-related integration protein 4), ID3 (DNA-binding protein inhibitor ID3), NKX3.1 (NK-3 transcription factor, locus 1) and SMAD1 (mothers against decapentaplegic homologue 1), were obtained from ThermoFisher Scientific. A control shRNA plasmid that encodes of a scrambled shRNA sequence was obtained from Santa Cruz Biotechnology (Santa Cruz, CA, USA). CWR22GFP cells were transfected with control shRNA or each shRNA using 
pGC-silencer-U6/Neo/GFP and selected using G418 to generate respective stable cell lines. In total, $1 \times 10^{4}$ stable cells with deficiencies of each gene were implanted into the dorsal lobe of each mouse's prostate $(n=12)$. In NOD-SCID male mice supplemented with dihydrotestosterone pellets $(0.2$ $\mathrm{mg} / \mathrm{mouse}$ embedded subcutaneously), the $\mathrm{GFP}^{+}$-metastatic foci in the lungs were visualised and counted at week 12 post-transplant with a Nikon SMZ1500 microscope.

\section{Flow cytometry cell sorting and the establishment of orthotopic tumour models}

Orthotopic Luc-CWR22 tumours were harvested at 2 weeks after implantation in mouse dorsal prostates. Single-cell suspension was prepared in phosphate-buffered saline (PBS) and incubated with FITC, APC, PE or PE-cy7-conjugated primary antibodies against ALDH (Stem Cell Technologies, Vancouver, Canada), CD44 (BD Biosciences, Bedford, MA, USA), CXCR4 (BD Biosciences), CD24 (BD Biosciences) or a2 $\beta 1$ (Millipore, Billerica, MA, USA), either individually or in combination. Flow cytometer (BD FACSAria III, San Jose, CA, USA) was used to separate $\mathrm{CD}_{4} 4^{+}$ $\mathrm{CD}_{4} 4^{+} \alpha 2 \beta 1^{+}-, \mathrm{ALDH}^{+} \mathrm{CD} 44^{+} \alpha 2 \beta 1^{+}$- and $\mathrm{ALDH}^{+} \mathrm{CD} 44^{+} \mathrm{CXCR}^{+} \mathrm{CD}_{2} 4^{+}$cell compartments. To purify $\mathrm{ALDH}^{+} \mathrm{CD} 44^{+} \mathrm{CXCR} 4^{+} \mathrm{CD} 24^{+}$cells from xenograft tumours, we incubated discrete cells with a FcR blocking agent (Miltenyi Biotec, San Diego, CA, USA) for $15 \mathrm{~min}$ at $4^{\circ} \mathrm{C}$. We then stained them with primary antibody to CXCR4 (cat\# 566282, BD Biosciences) for $30 \mathrm{~min}$ on ice, followed by staining with APC-conjugated goat anti-mouse IgG (cat\# 550826, BD Biosciences) for $15 \mathrm{~min}$ on ice. Cells were then washed three times and stained with PE-conjugated anti-CD44 antibody (cat\# 550989, BD Bioscience), followed by biotinylated anti-mouse H2-Kd (cat\# 130-107891, Miltenyi Biotec) for $20 \mathrm{~min}$ with the aim to remove mouse-origin cells. Next, purified cells were stained with PE-cy7-conjugated anti-CD24 (cat\# 561646, BD Biosciences), for 20 min. After washing with PBS, cells were incubated in a solution containing $1 \%$ bovine serum albumin (BSA) and $2.5 \mu \mathrm{g} / \mathrm{ml}$ insulin ( $1-6634$, Sigma). Then, the cells were suspended in an ALDEFLUOR assay buffer (ALDEFLUOR kit, Stem Cell Technologies) containing ALDH substrate $\left(1 \mu \mathrm{M}\right.$ per $1 \times 10^{6}$ cells). They were then incubated for $40 \mathrm{~min}$ at $37^{\circ} \mathrm{C}$ and sorted by fluorescence-activated cell sorting (FACS). Additional purification steps via BV711-conjugated antiCD31 (cat\# 745436, BD Biosciences), PE-Cy ${ }^{\mathrm{TM}} 5$-conjugated anti-CD3 (cat\# 555341, BD Biosciences) and PE-CF594-conjugated anti-CD14 (cat\# 562334, BD Biosciences) were applied to derived cells to deplete human endothelial cells, lymphocytes and monocytes, respectively. Each subset of cells $\left(1 \times 10^{3}\right)$ was resuspended in a mixture of $20 \mu \mathrm{l}$ medium and $20 \mu \mathrm{l}$ Matrigel, with or without TGF $\beta$ inhibitor SD208 (5 MM; Millipore). After $2 \mathrm{~h}$ of incubation at room temperature, cells were inoculated into mouse dorsal prostates with subcutaneous implantation of $0.2 \mathrm{mg}$ dihydrotestosterone into each mouse. Mice were sacrificed 120 days after implantation, and the primary tumours were harvested immediately. $\mathrm{Luc}^{+}$metastatic foci in nine organs (bilateral lungs and kidneys, pancreas, liver, spleen, brain and bone marrow) were visualised, and representative images were acquired using a Nikon SMZ1500 microscope (Nikon, Japan).

\section{Patient-derived xenograft (PDX) models}

Human PCa samples were obtained after radical prostatectomy, with the written informed consent from the patients in accordance with national and institutional guidelines and with the approval of the Ethics Committee of Shanghai Pudong Hospital and the Ethical Commission of Fudan University. Gleason grade was determined by two officially certified pathologists. PCa tissues with a Gleason score of 8 were minced into around $0.5 \mathrm{~mm}^{3}$ pieces, followed by PBS wash twice. Each piece was then embedded subcutaneously into the male NOD/SCID mouse, with the dihydrotestosterone pellet at $0.2 \mathrm{mg}$ per mouse embedded subcutaneously on the back $(n=7)$. When the xenograft tumour became palpable, it was harvested, and $\mathrm{ALDH}^{+} \mathrm{CD} 44^{+} \mathrm{CXCR} 4^{+} \mathrm{CD} 24^{+}$and $\mathrm{ALDH}^{-} \mathrm{CD} 44^{-} \mathrm{CXCR} 4^{-} \mathrm{CD} 24^{-}$ cells were isolated from xenograft tumours using FACS, respectively, as described above.

\section{HOXB9 overexpression}

In total, $1 \times 10^{6}$ Du-145-GFP cells were collected, washed with PBS and resuspended in Nucleofector Kit $\mathrm{V}$ buffer (Amaxa Biosystems, San Francisco, CA, USA). In all, $3 \mu \mathrm{g}$ of myc-coupled HOXB9-expressing vector (Amaxa Biosystems) was transfected into the cells using a Nucleofector device (Amaxa Biosystems), following the manufacturer's instructions. After $48 \mathrm{~h}$ of transfection, G418 was added to select and maintain the stable cells.

\section{HOXB9 and CD44 knockdown}

The vectors expressing HOXB9 shRNA (5'-CCC TTC AAT TTG TAG ACT CTT-3' and $5^{\prime}$-CTC CTC AAT CTG AGT GAG AGA-3'; ThermoFisher Scientific) and CD44 (5'-GAC CTC TGC AAG GCT TTC AAT-3' and 5'-ATT GAA AGC CTT GCA GAG GTC-3'; Santa Cruz Biotechnology) were transduced into Du-145 cells using FuGENE 6 (Roche Applied Science, Indianapolis, IN, USA) and Lipofectamine 2000 (Invitrogen, Carlsbad, CA, USA), respectively. Stable cells were selected and maintained using RPMI-1640 supplemented with $8 \% \mathrm{FBS}$.

\section{Semi-quantitative and quantitative RT-PCR}

Total RNAs were isolated from cells or tumour tissues using Trizol (Invitrogen), and reversely transcribed to produce CDNA using a RNeasy Extraction Kit (Qiagen, Valencia, CA, USA) according to the manufacturer's instructions. The primers for PCR are shown in Supplementary Table 2. For semi-quantitative RT-PCR, the following cycling conditions were performed: initial denaturation at $95^{\circ} \mathrm{C}$ for $4 \mathrm{~min}, 40$ cycles of $45 \mathrm{~s}$ at $94^{\circ} \mathrm{C}, 45$ $s$ at $60^{\circ} \mathrm{C}$ and $30 \mathrm{~s}$ at $72^{\circ} \mathrm{C}$; final extension at $72^{\circ} \mathrm{C}$ for $5 \mathrm{~min}$. The PCR products were analysed on $1.5 \%$ agarose gel. Images were imported with Image Lab (Bio-Rad, Hercules, CA, USA). The quantitative real-time PCR was performed in an ABI Prism 7000 Sequence Detector (Applied Biosystems, Foster City, CA, USA) using SYBR Green PCR Master Mix reagent as the detector, according to the manufacturer's instructions. Primer sequences were as follows: NanogP8 (forward) CGC CCT GCC TAG AAA AGA CAT TT, (reverse) ACG AGT TTG GAT ATC TाT AGG GTT TAG AAT C; $\beta$-actin (forward) CGC ACC ACT GGC ATT GTC AT, (reverse) TTC TCC TTG ATG TCA CGC AC. The target gene expression levels were normalised to the $\beta$-actin level using the comparative $C_{T}$ method. Data are presented as fold changes in expression relative to control.

\section{Western blot analysis}

Cell or tumour tissue lysates were collected and quantified following standard protocols. In total, $20 \mu \mathrm{g}$ of protein samples were separated by $12 \%$ sodium dodecyl sulfate-polyacrylamide gel electrophoresis, transferred to a nitrocellulose membrane, blocked for $1.5 \mathrm{~h}$ with Tris-buffered saline containing Tween 20 (TBST) containing 1\% BSA at room temperature, and incubated overnight with primary HOXB9 antibodies $(1: 1000$, mouse mAb, cat\# MA519117, clone 2E8, Invitrogen), TGFB2 (1:1000, mouse mAb, cat\# MAB612100, clone 8607, R\&D Systems, Minneapolis, MN, USA); MMP9 (1:1000, rabbit mAb, cat\# ab137867, clone EP1255Y, Abcam, Cambridge, MA, USA), CD133 (1:500, mouse mAb, cat\# MAB4399-I, clone 17A6.1, Millipore), SPP1 (1:1000, goat pAb, cat\# AF1433, R\&D Systems), Smad1 (1:1000, mouse mAb, cat\# 05-1459, clone AS22, Millipore), phospho-Smad1 (p-Smad1, 1:500, rabbit pAb, cat\# 06-702, Millipore), Smad2 (1:1000, rabbit mAb, cat\# 5339, clone D43B4, Cell Signaling Technology, Beverly, MA, USA), phospho-Smad2 (p-Smad2, 1:500, rabbit mAb, cat\# 18338, clone E8F3R, Cell Signaling Technology), Nanog (1:1000, mouse mAb, cat\# MABD24, clone 7F7.1, Millipore), Octamer-4 (OCT4, 1:1000, mouse mAb, cat\# MAB4419, clone 7F9.2, Millipore), Sox2 (1:1000, mouse mAb, cat\# MAB4423, clone 10H9.1, Millipore), FoxD3 (1:1000, rabbit mAb, cat\# 2019, clone D20A9, Cell Signaling Technology), ABCG2 (1:500, rabbit mAb, cat\# ab207732, clone EPR20080, Abcam), aldehyde dehydrogenase (ALDH, 1:1000, rabbit pAb, cat\# ABD12, Millipore), CXCR4 (1:1000, rabbit mAb, cat\# ab124824, clone UMB2, Abcam), PSA (1:1000, rabbit mAb, cat\# 5365S, clone D6B1, Cell Signaling Technology), CD44 (1:1000, mouse mAb, cat\# MA5-15462, clone 8E2F3, Invitrogen), CD24 (1:500, mouse mAb, cat\# ab179821, clone EPR3006N, Abcam), prostatic acidic phosphatase (PAP, mAb, cat\# MABN318, clone 3G10.1, Millipore), prostatespecific membrane antigen (PSMA, 1:1000, mAb, cat\# 12815S, clone D7l8E, Cell Signaling Technology), epithelial cadherin (E-cad, 1:1000, rabbit pAb, cat\# 07-697, Millipore), Slug (1:1000, rabbit mAb, cat\# 9585T, clone C19G7, Cell Signaling Technology), Vimentin (1:1000, mouse mAb, cat\# MABT121, clone 3 CB2, Millipore), GAPDH (1:1000, rabbit mAb, cat\# $2118 \mathrm{~S}$, clone $14 \mathrm{C} 10$, Millipore) and $\beta$-actin (1:2000, rabbit mAb, cat\# MABT523, clone RM112, Millipore) at $4^{\circ} \mathrm{C}$. The membranes were washed three times with TBST, then incubated with horseradish peroxidase-conjugated goat anti-rabbit or antimouse IgG or IgM (1:2000, Millipore) for $1 \mathrm{~h}$ at room temperature, and washed with TBST. The chemiluminescence signal was detected using ECL (Clinx Science Instruments, Shanghai, China), and developed on X-ray film. $\beta$-actin was used as an internal control.

\section{Wound-healing assay}

$\mathrm{ALDH}^{+} \mathrm{CD} 44^{+} \mathrm{CXCR4} 4^{+} \mathrm{CD} 24^{+}$cells were seeded into a 24-well plate at a density of $5 \times 10^{4}$ cells per well. They were then incubated either with or 
without $5 \mu \mathrm{M}$ TGF $\beta$ inhibitor SD208 in $600 \mu$ I DMEM containing $0.1 \%$ FBS at $37^{\circ} \mathrm{C}$ for $24 \mathrm{~h}$. A cell scraper was used to generate a $2 \mathrm{~mm}$-wide scratch line in the cell monolayer. Cells were allowed to migrate for $24 \mathrm{~h}$ and were stained with crystal violet. Cell counting was performed in ten randomly selected fields and images were captured using an inverted light microscope (IX71, Olympus).

\section{Transwell invasion assay}

A cell invasion assay was performed using 24-well BD biocoat Matrigel invasion chambers with 8.0- $\mu \mathrm{m}$ pores (BD Bioscience Discovery Labware, Bedford, MA, USA), according to the manufacturer's instructions. In total, $5 \times 10^{4} \mathrm{ALDH}^{+} \mathrm{CD} 44^{+} \mathrm{CXCR4}^{+} \mathrm{CD} 24^{+}$cells were loaded into a Matrigel $(100$ $\mu \mathrm{g} / \mathrm{ml}$; BD Biosciences; diluted at 1:20 with DMEM)-coated upper chamber filled with $500 \mu \mathrm{L}$ DMEM containing $0.1 \% \mathrm{FBS}$, either with or without $5 \mu \mathrm{M}$ TGF $\beta$ inhibitor SD208. To induce cell invasion, $600 \mu \mathrm{L} 10 \%$ FBS-containing DMEM was loaded into the lower chamber. After overnight incubation, the remaining non-invading cells in the upper chamber were removed with a cotton swab. The invading cells adhering to the lower surface were fixed and stained using crystal violet. The stained cells were counted in ten randomly selected fields, under an inverted light microscope (IX71), at $\times 4$ magnification.

\section{Cell proliferation assay}

Cells were seeded in 96-well plates at a density of $1 \times 10^{4}$ cells/well, and were treated with various chemotherapeutic agents for either 48 or $72 \mathrm{~h}$. Cell viability was measured with either AlamarBlue solution (Invitrogen) or WST-1 reagent (Beyotime, Shanghai, China) following the manufacturer's instructions. Chemotherapeutic agents and chemicals dimethylsulfoxide (DMSO), bicalutamide, abiraterone, docetaxel, etoposide and hydrogen peroxide $\left(\mathrm{H}_{2} \mathrm{O}_{2}\right)$ were purchased from Sigma. Charcoal dextran-stripped serum (CDSS) was obtained from Gemini (West Sacramento, CA, USA) and Enzalutamide was obtained from Selleck Chemicals (Houston, TX, USA).

\section{Flow-fluorescence in situ hybridisation (flow-FISH)}

Flow-FISH was conducted to measure the telomere length of the cells. Flow cytometer calibration, cell fixation, staining protocol and normalisation were conducted using mouse lymphoma cells with known telomere lengths. In all, $5 \times 10^{5} \mathrm{ALDH}^{+} \mathrm{CD}_{4} 4^{+} \mathrm{CXCR}^{+}{ }^{+} \mathrm{CD} 24^{+}$cells, $\mathrm{ALDH}^{-} \mathrm{CD}^{-} 4^{-}$ CXCR4 ${ }^{-} \mathrm{CD}^{-}$cells or mouse lymphoma cells were washed in hybridisation buffer and resuspended in hybridisation solution containing formamide and $0.3 \mu \mathrm{g} / \mathrm{ml}$ FITC-conjugated pentose nucleic acid (PNA) probe. Control samples were incubated in hybridisation solution without a PNA probe. Lymphoma cells were distinguished from cell derivatives by immunostaining with CD45 antibody (Millipore). The DNA content was quantified using propidium iodide staining. Cells were gated at G0/G1 based on DNA content, and the telomere fluorescence intensity was calculated, as previously described [30]. Detections were conducted on an FACSCanto flow cytometer (Becton Dickinson, Franklin Lakes, NJ, USA).

\section{Statistical analysis}

Statistical analyses were performed with SPSS 23.0 (SPSS Inc., Chicago, IL, USA). Unless stated otherwise, normally distributed data are presented as the mean \pm standard deviation of at least three independent experiments. Multiple groups were compared by ANOVA, followed by post hoc analysis (S-N-K test). When categorical data were compared, a chi-square test was used. A two-tailed $P$ value below 0.05 was considered statistically significant.

\section{RESULTS \\ HOXB9 is induced in orthotopic PCa tumours and is essential to PCa lung metastasis}

To compare the metastatic potentials of the orthotopically and ectopically implanted PCa tumours, we inoculated GFP-labelled PCa cells (CWR22, Du-145, LNCaP, LAPC4 and LAPC9) and RFP-labelled cells into the dorsal lobe of the prostate and a subcutaneous area of the same mouse, respectively. Metastases in nine organs, including bilateral lungs and kidneys, pancreas, liver, spleen, brain and bone marrow, were identified by detecting GFP or RFP (Fig. 1a and Supplementary Table 3). For all five kinds of PCa cells, the metastasis rates for dorsal prostate implantation were significantly higher than for those with subcutaneous implantation (Fig. 1b and Supplementary Table 3). To reveal the characteristic gene expression pattern underlying the increased metastatic potential of orthotopic PCa tumours, we next implanted CWR22-GFP cells with the highest metastasis rate into the dorsal prostate and a subcutaneous area of the same mouse. Then, we performed microarray analysis to identify the DEGs $(P<0.05$, fold change $\geq 2)$ between orthotopic and subcutaneous tumours. The 791 identified DEGs (602 upregulated and 189 downregulated) were functionally classified into 11 categories (I-XI; Fig. 1C), among which three categories (I, II and III) with the greatest fold changes were associated with tumour metastasis, CSC growth and inflammation/immunity, respectively. The top 50 upregulated genes are provided in an excel list (Supplementary Table 4). In addition, among the 50 most upregulated DEGs, 12 were associated with CSC growth regulation: CXCR4, CD133, ABCG2, CD24, HOXB9, NOS2A, TROP2, LRIG1, WNT4, ID3, NKX3.1 and SMAD1. To confirm whether these DEGs had contributed to the metastasis originating from the orthotopic tumours, we knocked down individual DEGs in CWR22-GFP cells which were then inoculated into mouse dorsal prostates and the lung metastases were detected. As shown in Fig. 1d, the numbers of pulmonary metastases significantly decreased in the mice which had received CSC-related gene-deficient CWR22 transplant cells, compared with the control. This suggests that these CSC-related DEGs are essential to CWR22 metastasis. Among them, knockdown of TROP2 and HOXB9 had the greatest inhibitory effects $(87 \%$ and $85 \%$, respectively) on CWR22 lung metastasis, suggesting that TROP2 and HOXB9 regulate PCa metastasis.

\section{HOXB9 is overexpressed in PCa and positively correlated with} Gleason scores

Since HOXB9 has been implicated in lung metastasis of breast carcinoma [25], we investigated the role of HOXB9 in PCa tissues. The results showed that HOXB9 was abundant in PCa tissues, but weak or not expressed in para-carcinoma and benign prostate hyperplasic tissues (Fig. 2a). These findings were consistent with HOXB9 protein expression in PCa tissues (Fig. 2b). Of note, the upregulation of HOXB9 mRNA was correlated with increased Gleason scores (Fig. 2c). As shown in Fig. 2d, the expression of HOXB9 was also upregulated in the orthotopic and subcutaneous tumours originated by LnCaP, DU154, LAPC4 and LPC9 cells. These findings suggested that HOXB9 may be involved in $\mathrm{PCa}$ development.

\section{HOXB9 regulates various tumour metastasis- and CSC growth-} related genes through TGF $\beta$ signalling

To investigate the mechanisms underlying the role of HOXB9 in PCa metastasis, we examined the effects of HOXB9 on the expression of a panel of representative genes from the top two DEG categories, namely tumour metastasis- and CSC growthrelated genes, in orthotopic implantation tumours. The results showed that the mRNA expression levels for TGF 32 , CD44, MMP9 and CD24 were significantly elevated in HOXB9-overexpressed PCa cells, compared with those in empty vector-transfected cells. Meanwhile, no significant difference in the mRNA expression of TGF $\beta 1$, Smad1, Smad2, osteopontin (SPP1) or CD133 was observed (Fig. 3a). However, the p-Smad2 protein levels (but not the total Smad2), SPP1 and MMP9 increased significantly in response to HOXB9 overexpression (Fig. 3b). Treatment with TGF $\beta$ inhibitor reversed these effects without affecting the HOXB9 protein expression (Fig. 3b). These data suggest that HOXB9 promotes TGF $32 / \mathrm{Smad} 2$, thus upregulating protein expression of downstream target genes such as SPP1 and MMP9. In addition, the knockdown of HOXB9 inhibited the protein expressions of TGF $\beta 2$, CD44 and CD24, compared with the control group (Fig. 3c). Meanwhile, CD44 knockdown had no effect on TGF $\beta 2$, Smad2 or p-Smad2 protein expression (Fig. 3d). This suggests that HOXB9 mediates the TGF $32 / \mathrm{Smad} 2 / \mathrm{CD} 44$ signalling cascade. 

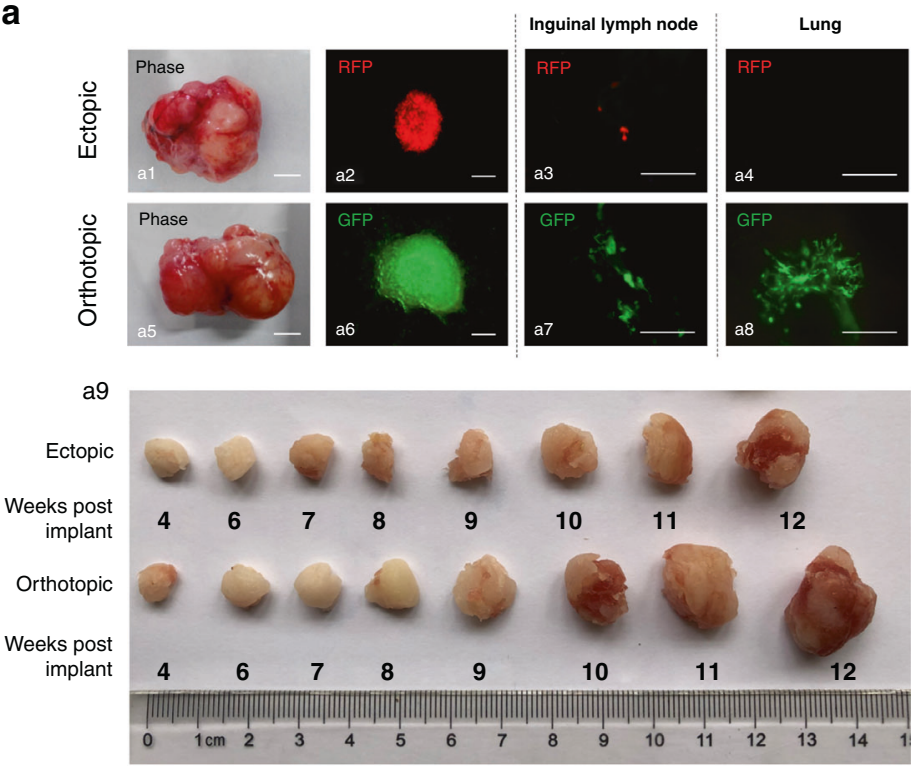

b

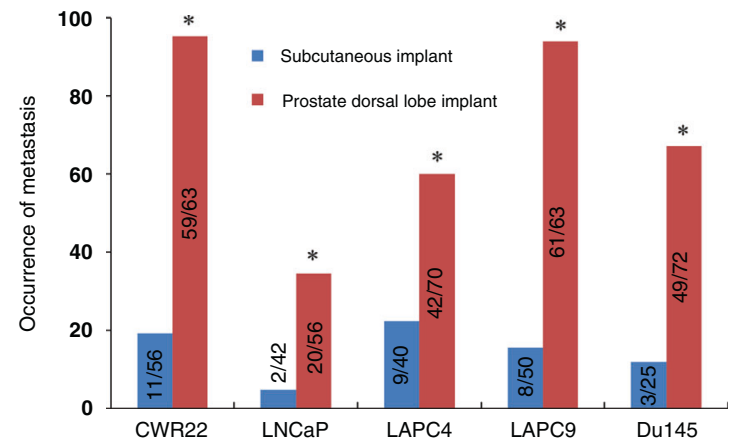$$
\text { CWR22 }
$$

C

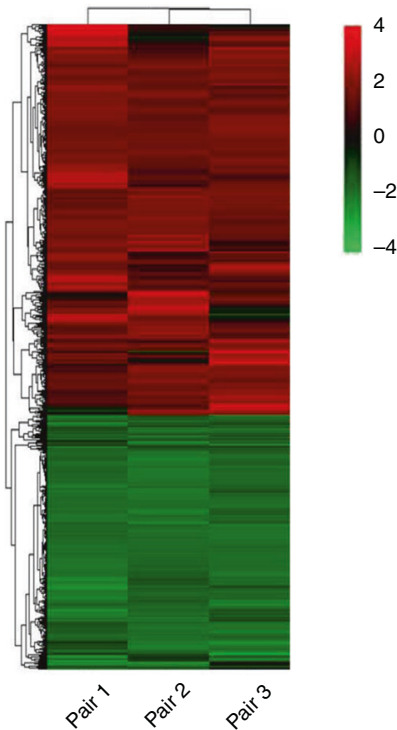

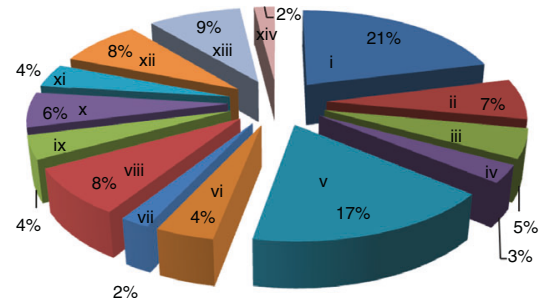

4
2
0
-2
-4

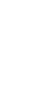

d

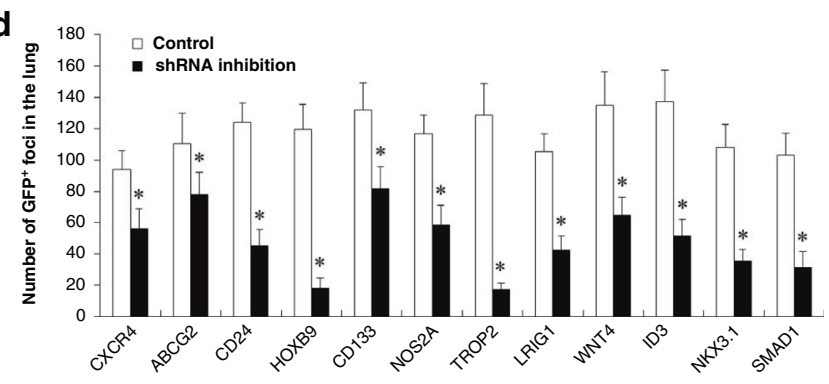

Fig. 1 HOXB9 is one of the differentially expressed genes (DEGs) in mouse orthotopic prostate tumours, compared with ectopically implanted tumours. Six- to eight-week-old NOD/SCID mice were used. Prostate cancer (PCa) cells (CWR22, LNCaP, LAPC4, LAPC9 or Du-145) expressing green and red fluorescent proteins (GFP and RFP) were implanted into the dorsal lobe of the prostate and a subcutaneous area of the same mouse, respectively. Mice were sacrificed at 2 months after the initial appearance of tumours, and the primary tumours were immediately harvested. GFP or RFP fluorescence in primary tumours, as well as in metastatic foci in nine organs (bilateral lungs and kidneys, pancreas, liver, spleen, brain and bone marrow), were visualised using Nikon SMZ1500 whole-mount epifluorescence dissecting microscopy. Representative images of GFP- (a1-a4) and RFP-labelled (a5-a8) primary tumours (a1-a2, a5-a6), lymph node (a3, a7) and lung (a4, a8) metastases, as well as cell implant-derived xenografts on the timeline of tumour growth (a9) are shown in (a). Scale bars, $2 \mathrm{~mm}$ for a1 and a5; $100 \mu \mathrm{m}$ for a2 and a6; $200 \mu \mathrm{m}$ for a3, a4, a7 and a8. b The metastasis rate was calculated as the total number of metastatic foci detected in each group/(the number of detected organs $\times$ mouse number in each group). ${ }^{*} P<0.05$ vs. the subcutaneous implant group. c CWR22-GFP cells with the highest metastasis rates were inoculated into the dorsal prostate and a subcutaneous area of the same mouse $(n=3)$. Microarray analysis was performed to identify the DEGs $(P$ $<0.05$, |fold change $\mid \geq 2$ ) in the orthotopic tumours compared with the subcutaneous ones (Pair I and II), as well as in the GFP ${ }^{+}$-tumour cells isolated from the orthotopic tumours compared with those from ectopic tumours (Pair III) at 12 weeks post transplantation. All samples were run in triplicate. A representative heatmap of orthotopic tumours and GFP $^{+}$-tumour cells derived from orthotopic tumours was obtained by hierarchical clustering. Red indicates the upregulated transcripts and green indicates the downregulated transcripts. The pie chart illustrates the classification of upregulated genes in orthotopic versus ectopic tumours. d Twelve CSC growth-related DEGs that were in the top 50 most upregulated DEGs were knocked down in CWR22-GFP cells using short hairpin RNAs, and cells with gene deficiencies were implanted into the mouse dorsal prostates ( $n=12 /$ group). At 12 weeks post-transplant, each mouse's GFP ${ }^{+}$-pulmonary metastases were counted. Data are presented as the mean $\pm \mathrm{SD}$ of the mean. ${ }^{*} P<0.05$ vs. control.

\section{$\mathrm{ALDH}^{+} \mathrm{CD}^{+}{ }^{+} \mathrm{CXCR4}^{+} \mathrm{CD}^{2} 4^{+}-\mathrm{PCa}$ cells exhibit stemness features in vitro and in vivo}

By comparing the gene expression profiles of orthotopic and subcutaneous PCa tumours, we selected five widely used CSC markers (ALDH, CD44, CXCR4, a2 $\beta 1$ and CD24) to sort candidate PCSCs from orthotopic PCa tumours. The five types of cell compartments of PCSCs were CD44 ${ }^{+}-, \mathrm{CD}_{4} 4^{+} \mathrm{a} 231^{+}{ }_{-}, \mathrm{ALDH}^{+} \mathrm{CD} 44^{+}$, $\mathrm{ALDH}^{+} \mathrm{CD} 44^{+} \alpha 2 \beta 1^{+}$- and $\mathrm{ALDH}^{+} \mathrm{CD} 44^{+} \mathrm{CXCR} 4^{+} \mathrm{CD} 24^{+}$- PCa cells. 


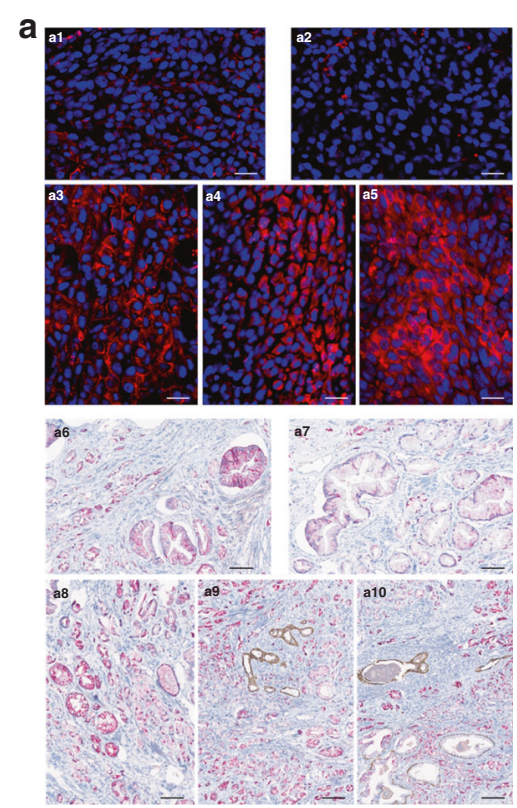

b
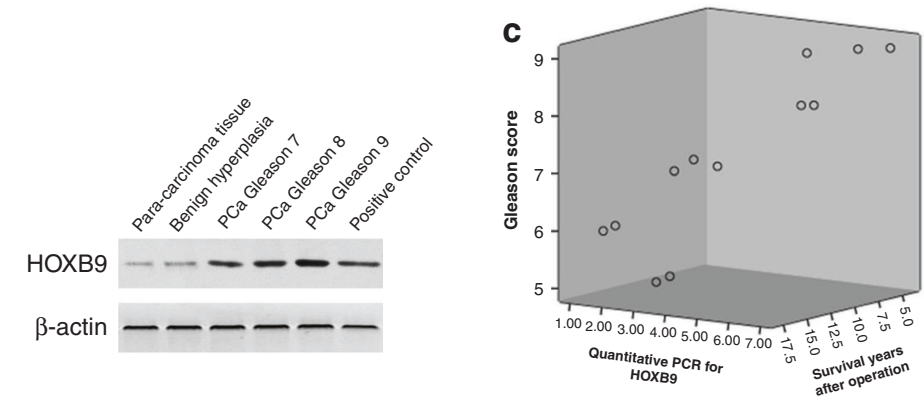

d

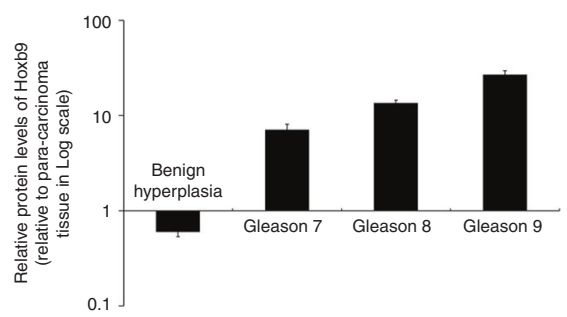

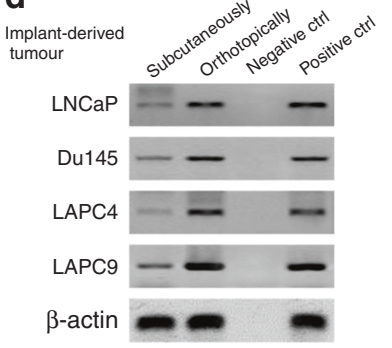

Fig. 2 HOXB9 expression in tumour tissues derived from PCa patients. The endogenous expression of HOXB9 protein was detected in paracarcinoma and PCa tissues with Gleason scores 7-9 from 32 patients with primary PCa, as well as prostate tissues from patients with benign prostate hyperplasia, using immunofluorescent staining (a, a1-a5), immunohistochemical staining (a, a6-a10) and western blot assay (b), respectively. a Morphological staining for HOXB9. a1-a5, Immunofluorescence study on HOXB9 (red) with nucleus counterstained by DAPI (blue); a6-a10, Immunohistochemical staining for HOXB9 (pink colour in the cytoplasm), as well as P63 (brown colour in the nucleus) and cytokeratin 18 (brown colour in the cytoplasm), with nucleus counterstained by hematoxylin (blue). a1-a10, representative images derived from para-carcinoma tissue (a1, a6), benign hyperplasia (a2, a7), prostate cancer tissue at Gleason score 7 (a3, a8), 8 (a4, a9) and 9 (a5, a10), respectively. Scale bars, $20 \mu \mathrm{m}$ for a1-a5, $100 \mu \mathrm{m}$ for a6-a10. b Western blotting for HOXB9 in tissues as indicated (upper panel) and quantitative analysis (lower panel, $n=8$ for each group). The positive control refers to breast cancer tissue derived from a breast cancer patient at the clinical stage of T4N2M0. c mRNA expression of HOXB9 was found to positively correlate with the Gleason score and negatively correlate with survival years after operation. Correlation analysis between HOXB9 expression levels and developmental stages of prostate cancer as well as prognosis suggested that HOXB9 mRNA levels were positively correlated with prostate cancer Gleason scores $(n=12, r=$ $0.918 ; P<0.01)$, and negatively correlated with prognostic survival years after radical prostatectomy $(n=12, r=-0.917 ; P<0.01)$. $\mathbf{d}$ Western blotting analysis on HOXB9, indicating the expression of HOXB9 is upregulated in the orthotopic vs subcutaneous tumours originated by LNCaP, DU154, LAPC4 and LAPC9 cells at 12 weeks post injection. Negative ctrl, negative controls (in which lane-specific antibodies were replaced with saline); positive ctrl, positive controls derived from human prostate cancer tissue of Gleason 8 after prostatectomy.
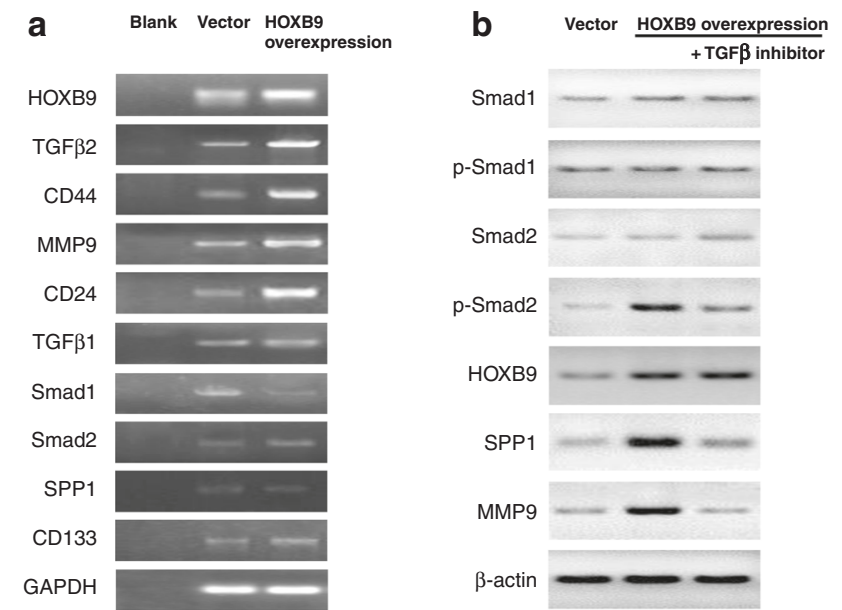

C

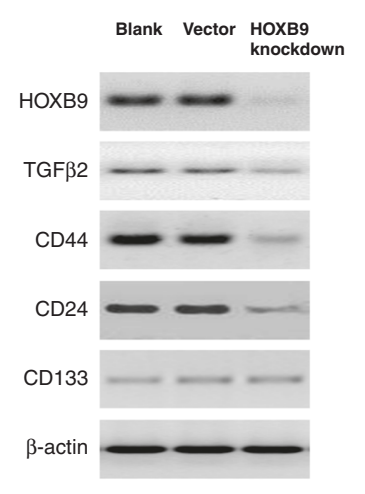

d

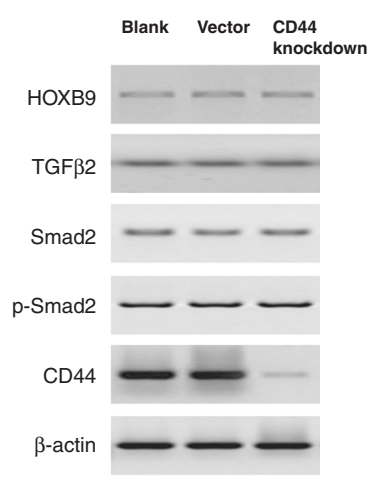

Fig. 3 HOXB9 regulates various tumour metastasis- and cancer stem cell (CSC) growth-related genes via transforming growth factor beta (TGF $\beta$ ) signalling. Du-145-GFP cells were stably transfected with myc-coupled vectors expressing HOXB9. a Semi-quantitative PCR was carried out to determine the mRNA expression of HOXB9, TGF 32 , CD44, MMP9, CD24, TGF $\beta 1$, Smad1, Smad2, osteopontin (SPP1) and CD133. GAPDH was used as an internal control. b Western blot analysis was performed to determine the protein levels of total Smad1, phospho (p)-Smad1, Smad2, p-Smad2, HOXB9, SPP1 and MMP9 in HOXB9-overexpressed Du-145-GFP cells, in the absence or presence of TGF $\beta$ inhibitor SD208 (5 $\mu \mathrm{M})$ for $2 \mathrm{~h}$. $\beta$-actin was used as an internal control. c HOXB9, TGF $\beta 2$, CD44, CD24 and CD133 protein levels were determined in Du-145-GFP cells with HOXB9 knockdown. d HOXB9, TGF $\beta 2$, total Smad2, p-Smad2 and CD44 protein levels were determined in Du-145-GFP cells with CD44 knockdown. An empty vector was used as a negative control. 
a

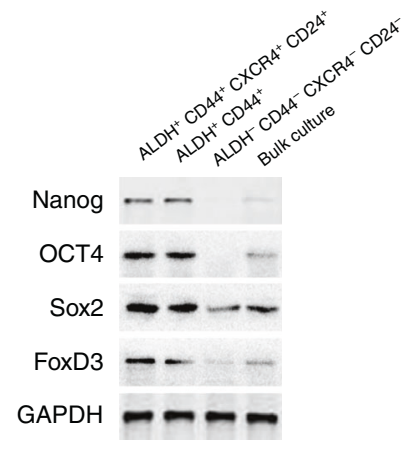

b

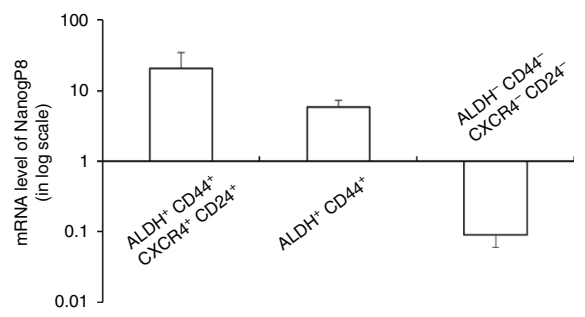

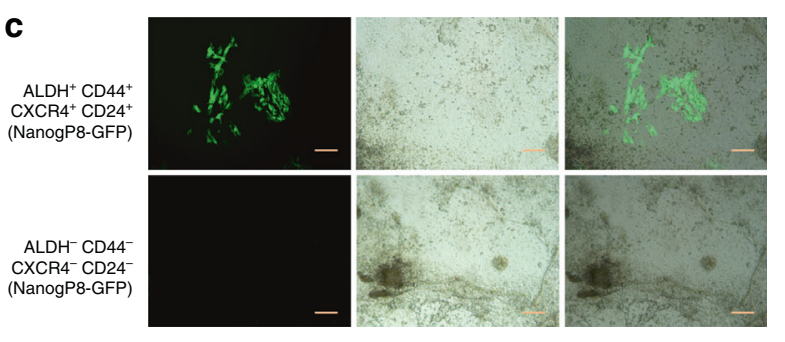

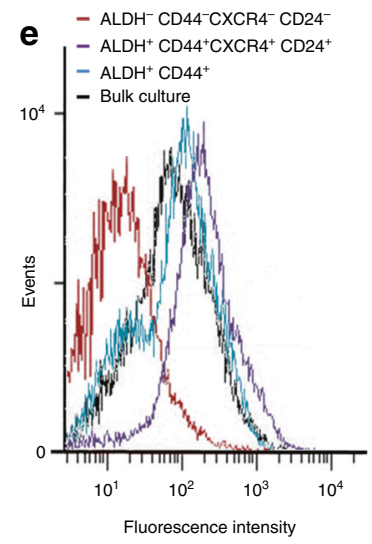

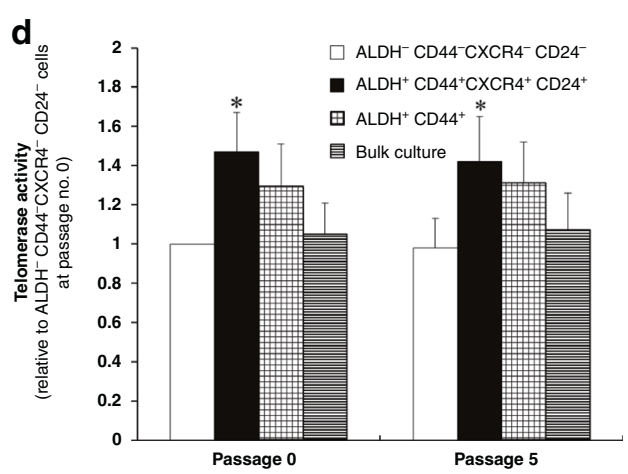

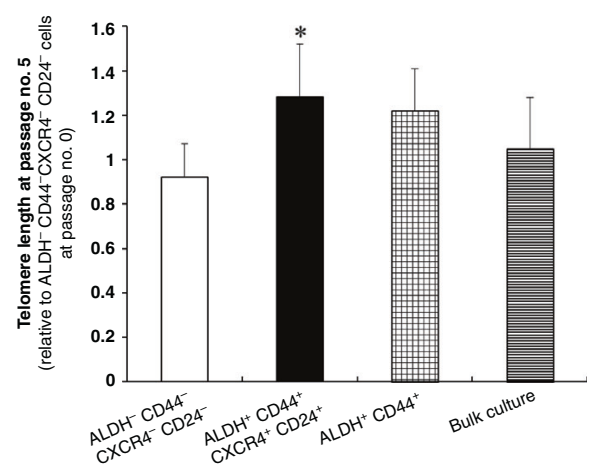

Fig. 4 Pluripotency-related features of $\mathbf{A L D H}^{+} \mathbf{C D 4 4}{ }^{+} \mathbf{C X C R 4}{ }^{+} \mathbf{C D 2 4}{ }^{+}-\mathbf{C W R 2 2}$ cells. a As shown by Western blotting analysis, $\mathrm{ALDH}^{+} \mathrm{CD} 44^{+}$ $\mathrm{CXCR}^{+} \mathrm{CD}^{2} 4^{+}-\mathrm{CWR} 22$ cells exhibit more robust expression of major pluripotency regulators such as Nanog, OCT4, Sox2 and FoxD3, as compared to $\mathrm{ALDH}^{+} \mathrm{CD}_{4}{ }^{+}-\mathrm{CWR} 22$ cells, $\mathrm{ALDH}^{-} \mathrm{CD}_{4} 4^{-} \mathrm{CXCR4^{- }}$ CD24--CWR22 cells and bulk culture. b Quantitative RT-PCR analysis demonstrated that $\mathrm{ALDH}^{+} \mathrm{CD}_{4}{ }^{+} \mathrm{CXCR}^{+}{ }^{+} \mathrm{CD} 24^{+}-\mathrm{PCa}$ cells have much higher expression level of NanogP8 mRNA, which was thought to be a pluripotency marker gene in cancer stem cells, as compared to controls run in parallel. c Cells labelled with reporter gene NanogP8-GFP, $1 \times$ $10^{3} \mathrm{ALDH}^{+} \mathrm{CD}_{4}{ }^{+} \mathrm{CXCR4}{ }^{+} \mathrm{CD} 24^{+}-\mathrm{CWR} 22$ cells could be differentiated into a mixed bulk culture in a "salt and pepper" pattern in vitro; whereas

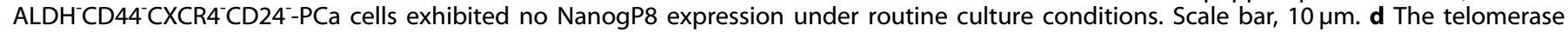
activity was measured by quantitative qRT-PCR. e Telomere fluorescence intensities and telomere length were measured by flow-fluorescence in situ hybridisation. Right panel, quantification of the left panel.

The results of the tumorsphere and colony-formation assays showed more floating tumorspheres and colonies formed by $\mathrm{ALDH}^{+}$ $\mathrm{CD} 44^{+} \mathrm{CXCR} 4^{+} \mathrm{CD} 24^{+}-\mathrm{PCa}$ cells cultured in CDSS-supplemented medium to mimic androgen deprivation than those in the control groups (Supplementary Fig. 1A-D). This indicated the enhanced tumour-initiation abilities of $\mathrm{ALDH}^{+} \mathrm{CD} 44^{+} \mathrm{CXCR} 4^{+} \mathrm{CD} 24^{+}$- PCa cells in vitro, under androgen-deprived conditions in vitro. In addition, in the tumour tissues derived from $\mathrm{ALDH}^{+} \mathrm{CD} 44^{+} \mathrm{CXCR} 4^{+} \mathrm{CD} 24^{+}-\mathrm{PCa}$ cells implanted into the dorsal lobe of NOD/SCID mouse prostates for 6 weeks, we observed the presence of CXCR4 ${ }^{-}$and (or) $\mathrm{CD}_{24}{ }^{-}$ cells (Supplementary Fig. 1E), suggesting that $\mathrm{ALDH}^{+} \mathrm{CD} 44^{+} \mathrm{CXCR4^{+ }}$ $\mathrm{CD} 24^{+}-\mathrm{PCa}$ cells are pluripotent and can differentiate into multiple progenies in vivo. Furthermore, we found that as few as ten $\mathrm{ALDH}^{+} \mathrm{CD} 44^{+} \mathrm{CXCR4}^{+} \mathrm{CD} 24^{+}-\mathrm{PCa}$ cells, but not other subsets, could develop a palpable tumour within 100 days of implantation.
Inoculation with $10^{2}$ or $10^{3} \mathrm{ALDH}^{+} \mathrm{CD} 44^{+} \mathrm{CXCR} 4^{+} \mathrm{CD} 24^{+}$-PCa cells produced the greatest tumour mass within the shortest time, as compared with three other sorted subpopulations (Supplementary Fig. 2A, B). In addition, the highest count of $\mathrm{ALDH}^{+} \mathrm{CD} 44^{+}$ $\mathrm{CXCR4}^{+} \mathrm{CD} 4^{+}$subset-derived metastatic foci was also observed in multiple organs (Supplementary Fig. $2 \mathrm{C}$ ). These results indicate that $\mathrm{ALDH}^{+} \mathrm{CD} 44^{+} \mathrm{CXCR} 4^{+} \mathrm{CD} 24^{+}-\mathrm{PCa}$ cells have tumorigenic and metastatic potential superior to other isogenic cells. Most protein expression levels of the major pluripotency regulators (Nanog, OCT4, Sox2 and FoxD3) [31-34], were found to increase significantly in $\mathrm{ALDH}^{+} \mathrm{CD} 44^{+} \mathrm{CXCR4}{ }^{+} \mathrm{CD} 24^{+}$-PCa cells, compared with those in the $\mathrm{ALDH}^{-} \mathrm{CD} 44^{-} \mathrm{CXCR} 4^{-} \mathrm{CD} 24^{-}$subsets (Fig. 4a).

The overexpression of NanogP8, an important paralog of the Nanog family [35], was observed in $\mathrm{ALDH}^{+} \mathrm{CD} 44^{+} \mathrm{CXCR} 4^{+} \mathrm{CD} 24^{+}$PCa cells. This was evidenced by the dramatically upregulated 


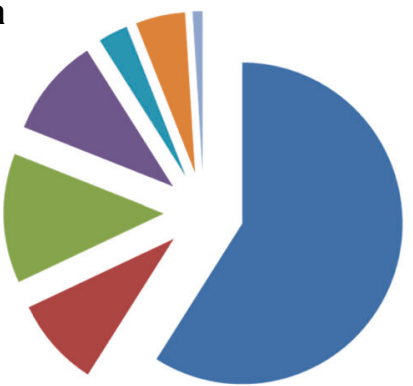

b $\mathrm{ALDH}^{+} \mathrm{CD} 44^{+}: \mathrm{ALDH}^{-} \mathrm{CD} 44^{-}$ $\mathrm{CXCR}^{+}{ }^{+} \mathrm{CD} 24^{+} \quad \mathrm{CXCR}^{-} \mathrm{CD} 24^{-}$

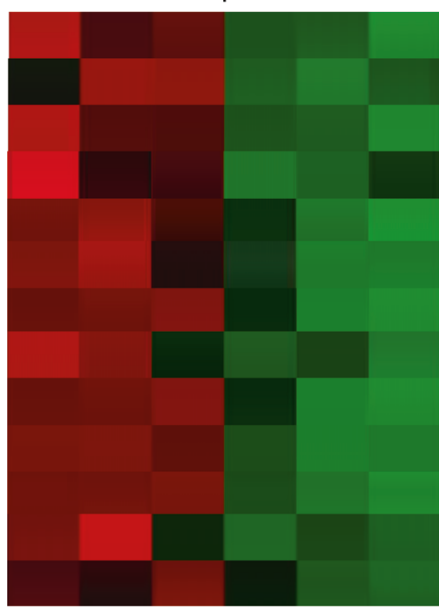

ABCG2

bcl-2

APLN

$\mathrm{H} 1 \mathrm{~F}-1 \alpha$

PLAU

THBS1

MSH6

REV1

XPA

GSTT2

Metallothionein

PSME3

ZBTB7A

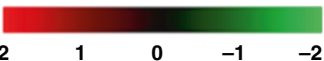

g

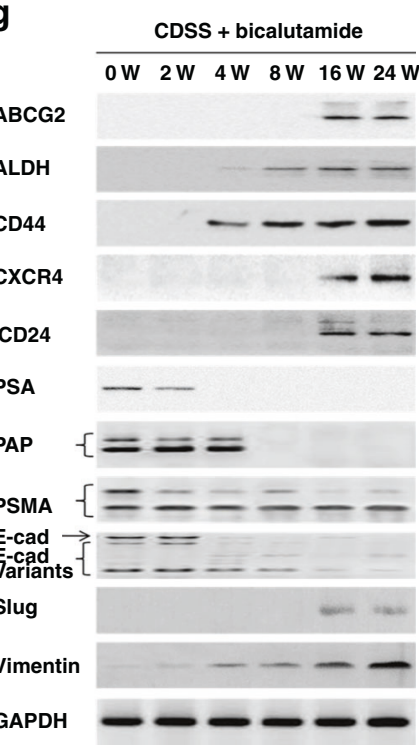
(59\%) \%) (3\%)

signaling )

ZBTB7A
Unclassified genes

Hypoxia tolerance

\& developmenta rocesses (13\%)

metabolism
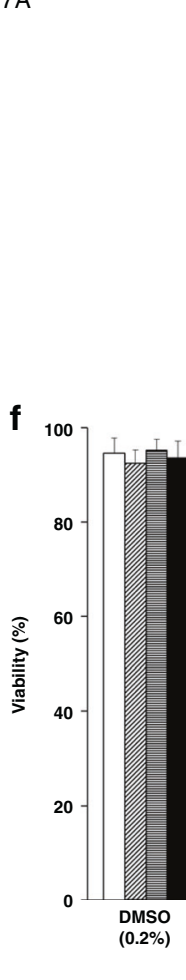

mRNA (Fig. 4b) and protein expression (Fig. 4c), compared with the $\mathrm{ALDH}^{-} \mathrm{CD} 44^{-} \mathrm{CXCR} 4^{-} \mathrm{CD} 24^{-}$subpopulation. In addition, the $\mathrm{ALDH}^{+} \mathrm{CD}_{4} 4^{+} \mathrm{CXCR} 4^{+} \mathrm{CD} 24^{+}$-PCa cells exhibited increased telomerase activity and longer telomeres than the $\mathrm{ALDH}^{-}$ $\mathrm{CD}_{4} 4^{-} \mathrm{CXCR}^{-}{ }^{-} \mathrm{CD} 24^{-}-\mathrm{PCa}$ cells, and these trends persisted for at least five passages (Fig. 4 d, e). The increased telomerase activity and longer telomeres are two important factors for maintaining
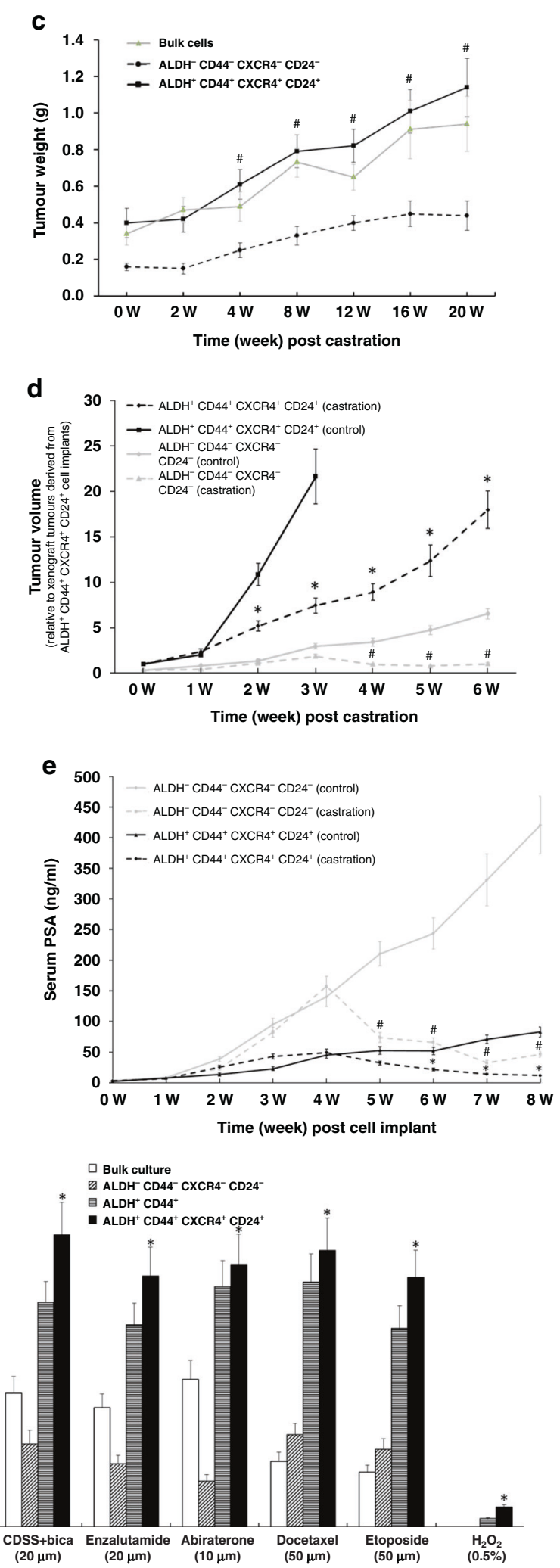

stem cell pluripotency [36]. These findings suggest that specific CSC markers may be correlated with tumorigenesis and metastasis. Collectively, our data demonstrate that orthotopic PCa tumour-derived $\mathrm{ALDH}^{+} \mathrm{CD} 44^{+} \mathrm{CXCR} 4^{+} \mathrm{CD} 24^{+}$cell compartment is a maintainable subpopulation of pluripotent PCSCs with more tumorigenic and metastatic potential than other isogenic PCa cells. 
Fig. 5 Castration resistance of $\mathrm{ALDH}^{+} \mathrm{CD}_{4}{ }^{+} \mathbf{C X C R 4}{ }^{+} \mathrm{CD24}{ }^{+}$-PCa cells. a A microarray analysis was performed to identify the $\mathrm{DEGs}(P<0.05$, fold change $\geq 2$ ) between $\mathrm{ALDH}^{+} \mathrm{CD} 44^{+} \mathrm{CXCR} 4{ }^{+} \mathrm{CD} 24^{+}$- and $\mathrm{ALDH}^{-} \mathrm{CD} 44^{-} \mathrm{CXCR} 4^{-} \mathrm{CD} 24^{-}-\mathrm{CWR} 22$ cells. The pie chart illustrates how the DEGs were classified. b A heatmap obtained by hierarchical clustering shows the altered genes ( $>2.0-$ fold) between these two subsets of cells. Purified $\mathrm{ALDH}^{+} \mathrm{CD} 44^{+} \mathrm{CXCR} 4^{+} \mathrm{CD} 24^{+}$- and $\mathrm{ALDH}^{-} \mathrm{CD} 44^{-} \mathrm{CXCR} 4^{-} \mathrm{CD} 24^{-}$-CWR22 cells were subcutaneously implanted into male NOD-SCID mice. When tumours became palpable, the mice were treated with castration and bicalutamide, in combination. Tumour weights (c), tumour

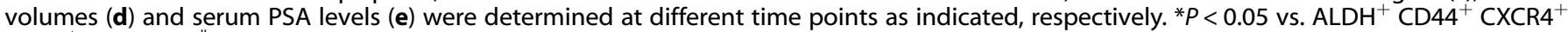
$\mathrm{CD}_{24}^{+}$(control); ${ }^{\prime} P<0.05$ vs. ALDH ${ }^{-} \mathrm{CD}_{4}{ }^{-} \mathrm{CXCR}^{-} \mathrm{CD}^{-} 4^{-}$(control). f CWR22 xenograft derived bulk cells, $\mathrm{ALDH}^{-} \mathrm{CD}^{-} 4^{-} \mathrm{CXCR}^{-} \mathrm{CD}^{-} 4^{-}{ }^{-}$, $\mathrm{ALDH}^{+} \mathrm{CD}_{4}{ }^{+}$-, and $\mathrm{ALDH}^{+} \mathrm{CD}_{4}{ }^{+} \mathrm{CXCR} 4^{+} \mathrm{CD} 24^{+}$-cells were plated in 96-well plates at a density of $1 \times 10^{4} /$ well and treated with different antiandrogens (as indicated) and chemotherapeutic agents, with $0.2 \%$ DMSO and $0.5 \% \mathrm{H}_{2} \mathrm{O}_{2}$ were used as negative and positive controls, respectively. After $48 \mathrm{~h}$ of treatment, cells were incubated with alamarBlue solution for $4 \mathrm{~h}$, and cell viability was measured with excitation

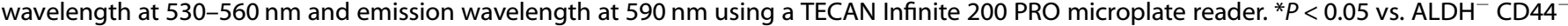
CXCR4 ${ }^{-}$CD24 $4^{-}$cells as well as bulk culture. $\mathrm{g}$ Western blot analysis was conducted to show time-dependent changes in phenotypic molecules and epithelial-mesenchymal transition-associated genes in $\mathrm{ALDH}^{-} \mathrm{CD}_{4} 4^{-} \mathrm{CXCR} 4^{-} \mathrm{CD} 24^{-}$cells derived from CWR22 xenograft in the presence of CDSS and bicalutamide $(10 \mu \mathrm{M})$.

\section{$\mathrm{ALDH}^{+} \mathrm{CD}^{+} 4^{+} \mathrm{CXCR4}^{+} \mathrm{CD}^{+} 4^{+}$-PCa cells are resistant to $^{-}$ surgical and chemical castration}

To investigate the mechanism underlying the superior abilities of tumour initiation, formation, invasion and metastasis of the $\mathrm{ALDH}^{+} \mathrm{CD}_{4}{ }^{+} \mathrm{CXCR4}^{+} \mathrm{CD}_{2} 4^{+}$subpopulation, we performed microarray analysis to identify the DEGs between the $\mathrm{ALDH}^{+}$ $\mathrm{CD}_{4} 4^{+} \mathrm{CXCR}^{+}{ }^{+} \mathrm{CD} 24^{+}-$and $\mathrm{ALDH}^{-} \mathrm{CD}_{4} 4^{-} \mathrm{CXCR} 4^{-} \mathrm{CD} 24^{-}-\mathrm{PCa}$ cells. The identified DEGs, such as ABCG2, bcl-2 and APLN, were functionally classified into seven categories (Fig. $5 a, b$ ). In the ectopic tumour model receiving castration and bicalutamide therapy, massive solid tumours were observed in $\mathrm{ALDH}^{+} \mathrm{CD} 44^{+} \mathrm{CXCR}^{+} \mathrm{CD} 24^{+}$-cell-injected mice, whereas the $\mathrm{ALDH}^{-} \mathrm{CD} 44^{-} \mathrm{CXCR}^{-}{ }^{-} \mathrm{CD} 24^{-}$cells yielded smaller tumours (Fig. $5 \mathrm{C}$, d). It was noted that the serum PSA level in $\mathrm{ALDH}^{+} \mathrm{CD} 44^{+} \mathrm{CXCR} 4^{+}$ $\mathrm{CD} 24^{+}$-cell-injected mice, either in the castration group or in control, was significantly lower than that in $\mathrm{ALDH}^{-} \mathrm{CD} 44^{-} \mathrm{CXCR} 4^{-}$ $\mathrm{CD} 24^{-}$-cell-injected mice, respectively, indicating a similar scenario with clinical setting (Fig. 5e). These data suggest that $\mathrm{ALDH}^{+} \mathrm{CD}_{4}{ }^{+} \mathrm{CXCR} 4{ }^{+} \mathrm{CD} 24^{+}$-cell-derived tumours may be less sensitive to androgen deprivation/antiandrogen therapy than those derived from $\mathrm{ALDH}^{-} \mathrm{CD} 44^{-} \mathrm{CXCR} 4^{-} \mathrm{CD} 24^{-}$cells. Indeed, the cell viabilities of $\mathrm{ALDH}^{+} \mathrm{CD} 44^{+} \mathrm{CXCR} 4^{+} \mathrm{CD} 24^{+}$cells were significantly higher than those of other subpopulations, in response to a broad spectrum of chemotherapeutic agents (Fig. 5f). These data suggest that $\mathrm{ALDH}^{+} \mathrm{CD} 44^{+} \mathrm{CXCR} 4^{+} \mathrm{CD} 24^{+}$cells are resistant to surgical/chemical castration therapy. To reveal the mechanism underlying cell castration resistance, we next isolated $\mathrm{ALDH}^{-} \mathrm{CD} 44^{-} \mathrm{CXCR}^{-} \mathrm{CD} 24^{-}$cells from CWR22 xenografts, which were then exposed to anti-androgens (CDSS plus bicalutamide) at different time points $(0,2,4,8,16$ and 24 weeks). We then determined the protein expression of a panel of PCSC markers, differentiation markers, and epithelial-mesenchymal transition (EMT)-related genes. As shown in Fig. $5 \mathrm{~g}$, the PCSC marker protein levels (ABCG2, ALDH, CD44, CXCR4 and CD24) were timedependently elevated. This suggests the antiandrogen-induced phenotypic conversion of $\mathrm{ALDH}^{-} \mathrm{CD} 44^{-} \mathrm{CXCR} 4^{-} \mathrm{CD} 24^{-}$cells into $\mathrm{ALDH}^{+} \mathrm{CD} 44^{+} \mathrm{CXCR} 4^{+} \mathrm{CD} 24^{+}$cells. In addition, the timedependent regulations of EMT-related genes (downregulation of E-cadherin, and upregulation of Slug and Vimentin) and downregulation of differentiation markers (PSA, PAP and PSMA) indicated a gradual EMT induction by anti-androgens. Collectively, these results suggest that chemoresistance in PCa may at least be partially attributable to the antiandrogen-induced phenotypic conversion and EMT in tumour cells.

\section{HOXB9 is more abundant in human high-grade PCa tissues which harbour $\mathrm{ALDH}^{+} \mathrm{CD}^{+}{ }^{+} \mathrm{CXCR4}^{+} \mathrm{CD}^{+} 4^{+}$subpopulation and silencing HOXB9 enhanced the sensitivity to various chemotherapeutic agents and decreased the metastatic ability of $\mathrm{ALDH}^{+} \mathrm{CD} 44^{+} \mathrm{CXCR4}^{+} \mathrm{CD}^{2} 4^{+}$cells}

To explore this study's clinical relevance, we determined the protein expression of ALDH, CD44, CXCR4 and CD24 in human PCa tissues. As shown in Fig. 6a and b, when compared with those in low-grade PCa tissues with Gleason scores of 6 (control), the ALDH, CD44, CXCR4 and CD24 protein levels were generally elevated in para-carcinoma tissues. They were also elevated in initial PCa tissues collected at first diagnosis or after recurrence via radical prostatectomy, as well as in refractory PCa tissues. Of these, the protein levels in the refractory PCa tissues were the highest, suggesting the presence of $\mathrm{ALDH}^{+} \mathrm{CD} 44^{+} \mathrm{CXCR} 4^{+} \mathrm{CD} 24^{+}$tumour cells in human PCa tissues. The same trend was also observed in HOXB9 protein expression. This was consistent with the in vitro observations, as well as those from mouse models. To confirm the existence of $\mathrm{ALDH}^{+} \mathrm{CD} 44^{+} \mathrm{CXCR} 4^{+} \mathrm{CD} 24^{+}$cells in human $\mathrm{PCa}$ tissues, we established a PDX model by subcutaneously implanting human PCa tissues into NOD-SCID mice. As expected, we isolated $\mathrm{ALDH}^{+} \mathrm{CD} 44^{+} \mathrm{CXCR} 4^{+} \mathrm{CD} 24^{+}$cells from the tumour derived from the PDX model by cell sorting. In addition, the results of a cell proliferation assay showed that there were more PDX model-derived $\mathrm{ALDH}^{+} \mathrm{CD} 44^{+} \mathrm{CXCR} 4^{+} \mathrm{CD} 24^{+}$cells than PDX model-derived bulk cells or $\mathrm{ALDH}^{-} \mathrm{CD} 44^{-} \mathrm{CXCR} 4^{-} \mathrm{CD} 24^{-}$cells when there was exposure to various chemotherapeutic drugs. Also, silencing HOXB9 in $\mathrm{ALDH}^{+} \mathrm{CD}_{4} 4^{+} \mathrm{CXCR} 4^{+} \mathrm{CD} 24^{+}$cells significantly improved their sensitivities to various chemotherapeutic agents (Fig. 6c, d). Tumours derived from HOXB9 knockdown $\mathrm{ALDH}^{+} \mathrm{CD} 44^{+} \mathrm{CXCR} 4^{+} \mathrm{CD} 24^{+}$cells exhibited significantly decreased expression of hypoxia tolerance-related genes (APLN, HIF-1a), DNA damage repair-related gene (MSH6), detoxificationrelated genes (GSTT2, metallothionein), chemoresistant gene ABCG2, and anti-apoptotic gene Bcl-2 (Fig. 6e), and significantly decreased levels of epithelial-mesenchymal transition-associated genes (Slug and Vimentin) (Fig. 6f), as compared to those derived from intact $\mathrm{ALDH}^{+} \mathrm{CD}_{4} 4^{+} \mathrm{CXCR} 4^{+} \mathrm{CD} 24^{+}$-cell injection. Orthotopic tumour models were developed from $\mathrm{CD} 44^{+}, \mathrm{CD} 44^{+} \mathrm{a} 2 \beta 1^{+}$, $\mathrm{ALDH}^{+} \mathrm{CD}_{4}{ }^{+} \mathrm{a} 2 \mathrm{B1}^{+}$and $\mathrm{ALDH}^{+} \mathrm{CD}_{4}{ }^{+} \mathrm{CXCR}^{+} \mathrm{CD}^{+} 4^{+}$cells with or without HOXB9 knockdown. The time for developing a palpable tumour in $\mathrm{HOXB9}$ knockdown $\mathrm{ALDH}^{+} \mathrm{CD} 44^{+} \mathrm{CXCR} 4^{+}$ $\mathrm{CD} 24^{+}$cells was significantly longer than that of $\mathrm{ALDH}^{+} \mathrm{CD} 44^{+}$ $\mathrm{CXCR}^{+}{ }^{+} \mathrm{CD} 24^{+}$cells (Fig. $6 \mathrm{~g}$ ), and the tumour weights (Fig. $6 \mathrm{~h}$ ), and the number of metastatic foci (Fig. 6i) were significantly decreased in HOXB9 knockdown $\mathrm{ALDH}^{+} \mathrm{CD} 44^{+} \mathrm{CXCR} 4^{+} \mathrm{CD} 24^{+}$ cells compared with those of $\mathrm{ALDH}^{+} \mathrm{CD} 44^{+} \mathrm{CXCR} 4^{+} \mathrm{CD} 24^{+}$cells. Taken together, these finding indicated that HOXB9 is highly expressed in human high-grade $\mathrm{PCa}$ which is enriched with $\mathrm{ALDH}^{+} \mathrm{CD}_{4}{ }^{+} \mathrm{CXCR4}^{+} \mathrm{CD}^{+} 4^{+}$cells and silencing HOXB9 significantly improved the sensitivity to various chemotherapeutic agents and decreased the metastatic ability of $\mathrm{ALDH}^{+} \mathrm{CD} 44^{+} \mathrm{CXCR}^{+}{ }^{+} \mathrm{CD} 24^{+}$cells.

\section{HOXB9/TGF $\beta 2$ contributes to the superior tumorigenic and metastatic potential of the $\mathrm{ALDH}^{+} \mathrm{CD}^{+} 4^{+} \mathrm{CXCR4}^{+} \mathrm{CD}^{+}{ }^{+}$ subpopulation derived from the $\mathrm{PCa}$ xenograft}

To explore whether the HOXB9/TGF 32 signalling is involved in the superior tumorigenic and metastatic potential of the 
a

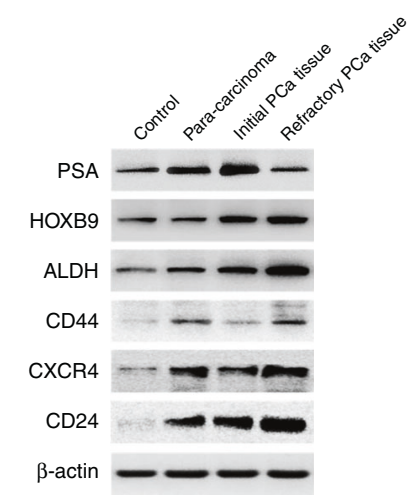

b

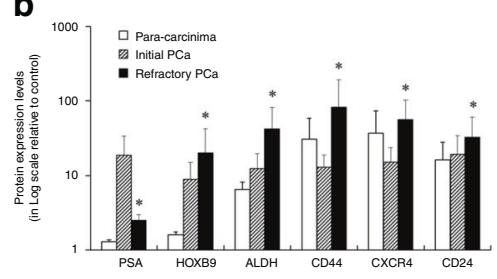

C

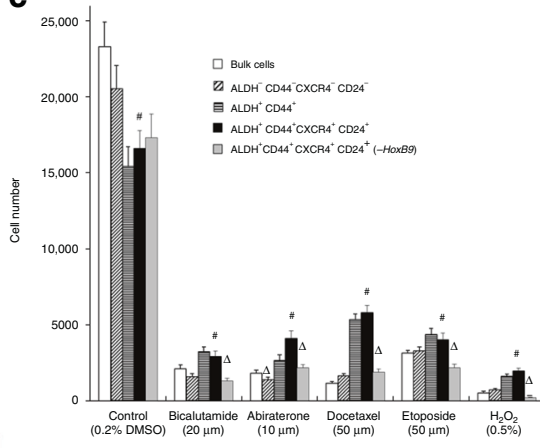

g

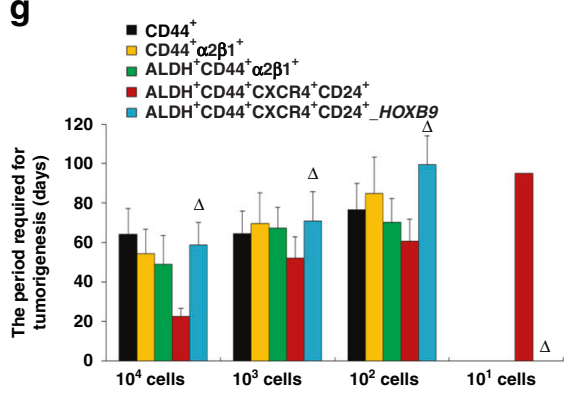

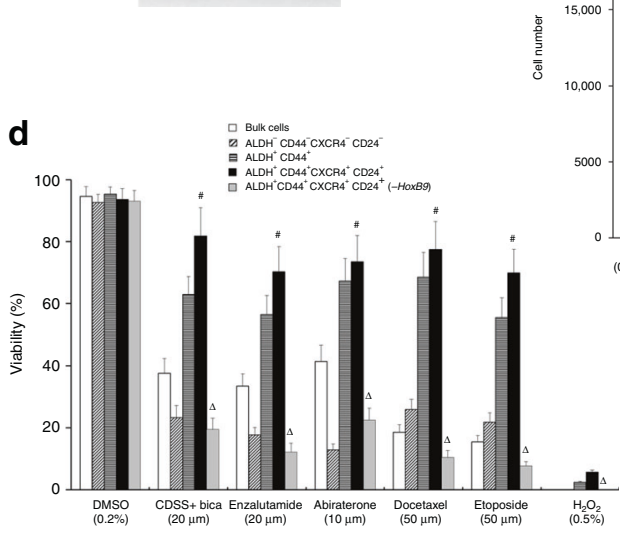

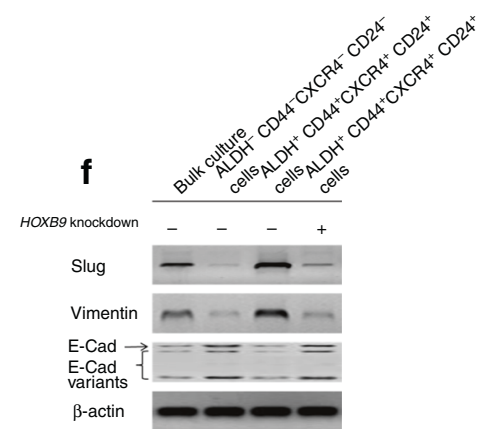

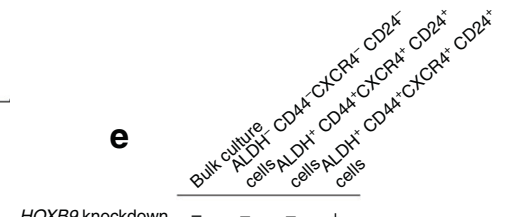

HOXB9 knockdown

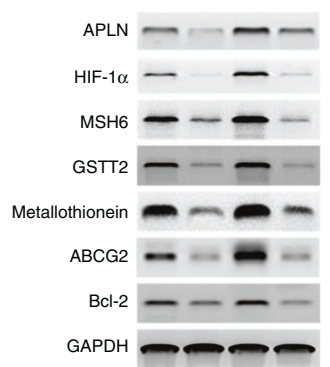

i

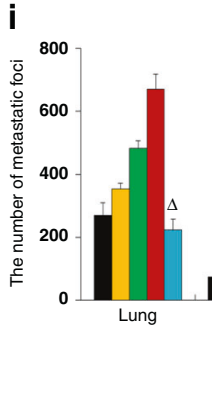

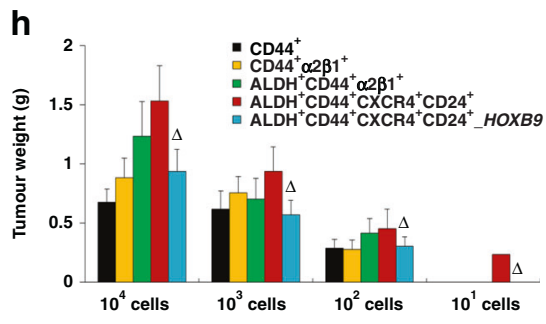

Fig. 6 The $\mathrm{ALDH}^{+} \mathrm{CD44}^{+} \mathrm{CXCR4}^{+} \mathrm{CD24}^{+}$subpopulation in human PCa tissues. a Western blot analysis was performed to determine the protein expressions of PSA, HOXB9, ALDH, CD44, CXCR4 and CD24 in the controls (PCa tissue with Gleason score 6), para-carcinoma (2 mm away from PCa tissue), initial PCa tissue (derived from PCa at first diagnosis via radical prostatectomy) and refractory PCa tissue (derived after recurrence), respectively. $\beta$-actin was used as an internal control. b Quantification of (a). ${ }^{*} P<0.05$ vs. initial PCa tissues. ( $\left.n=6\right)$. c Human PCa tissue was subcutaneously implanted into NOD-SCID mice to establish a patient-derived xenograft (PDX) model. Subsets of cells (as indicated) were derived from the PDX model and seeded in 96-well plates $\left(1 \times 10^{4}\right.$ cells/well) and treated with different anti-androgens (as indicated) and chemotherapeutic agents, with $0.2 \%$ DMSO and $0.5 \% \mathrm{H}_{2} \mathrm{O}_{2}$ were used as negative and positive controls, respectively. After $48 \mathrm{~h}$ of treatment, cells were incubated with alamarBlue solution for $4 \mathrm{~h}$, and cell viability was measured with excitation wavelength at $530-560 \mathrm{~nm}$ and emission wavelength at $590 \mathrm{~nm}$ using a TECAN Infinite 200 PRO microplate reader. d Subsets of cells (as indicated) were derived from the PDX model and seeded in 96 -well plates $\left(1 \times 10^{4}\right.$ cells/well). Cells were treated with different chemotherapeutic drugs, as indicated, for $72 \mathrm{~h}$. Then, a WST1 proliferation assay was performed. The absorbance was measured at $450 \mathrm{~nm}$ using a microplate reader. ${ }^{*} P<0.05$ vs. bulk cells, as well as

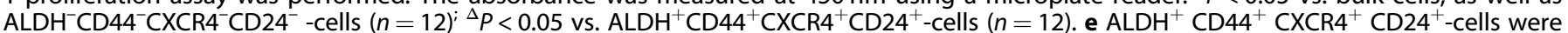
isolated from PDX tumours at 8 weeks post implantation, before they were subject to HOXB9 knockdown. Then cells at $1 \times 10^{6}$ (together with $1 \times 10^{6} \mathrm{HS}-5$ cells to facilitate tumour formation) were subcutaneously injected into the NOD/SCID mouse. Derived tumours at 12 weeks post injection were subject to Western blotting analysis of the expression of APLN, HIF-1 $\alpha$, MSH6, GSTT2, metallothionein, ABCG2 and BCl-2). GAPDH was used as an internal control. $\mathbf{f}$ Western blotting analysis of the expression of epithelial-mesenchymal transition-associated genes (Slug, Vimentin and E-cadherin). $\beta$-actin was used as an internal control. (G-I) CD44 ${ }^{+}-, \mathrm{CD}_{4} 4^{+} \alpha 2 \beta 1^{+}-, \mathrm{ALDH}^{+} \mathrm{CD} 4^{+} \alpha 2^{\beta} 1^{+}-$and $\mathrm{ALDH} \mathrm{C}^{+} \mathrm{CD} 44^{+}$ $\mathrm{CXCR4}^{+} \mathrm{CD}^{2} 4^{+-}$PCa cells were obtained from orthotopic CWR22 tumours by FACS using the respective antibodies, whereas HOXB9-silenced $\mathrm{ALDH}^{+} \mathrm{CD}_{4}{ }^{+} \mathrm{CXCR4}^{+} \mathrm{CD} 24^{+}$-PCa cells were derived from ALDH ${ }^{+}$CD44 ${ }^{+}$CXCR4 ${ }^{+} \mathrm{CD} 24^{+}$-cells. Orthotopic tumour models were established using these subsets of cells, respectively. Mice were sacrificed at week 14 after inoculation. The time for developing a palpable tumour (g), tumour weights $(\mathbf{h})$ and the number of metastatic foci (i) were recorded $(n=12) .{ }^{\Delta} p<0.05$ vs. ALDH ${ }^{+} \mathrm{CD}_{4} 4^{+} \mathrm{CXCR}^{+}$CD24 ${ }^{+}$cells-based implantation. 
$\mathrm{ALDH}^{+} \mathrm{CD} 44^{+} \mathrm{CXCR}^{+}{ }^{+} \mathrm{CD} 24^{+}$subset, we determined the protein expressions of HOXB9 and TGF $\beta 2$ in different cell subsets isolated from CWR22 cell xenograft. As shown in Supplementary Fig. 3A, the protein levels of both HOXB9 and TGF $\beta 2$ were elevated in $\mathrm{ALDH}^{+} \mathrm{CD}_{4} 4^{+} \mathrm{CXCR}^{+}{ }^{+} \mathrm{CD} 24^{+}$cells, compared with the unsorted and other subsets of cells. Furthermore, TGF $\beta$ inhibitor significantly retarded tumour formation, while reducing cell migration and invasion abilities, tumour mass, and the number of metastatic foci derived from orthotopically implanted $\mathrm{ALDH}^{+} \mathrm{CD} 44^{+} \mathrm{CXCR} 4^{+}$ $\mathrm{CD}_{24}{ }^{+}$subpopulation (Supplementary Fig. 3B-F). This suggests that the high tumorigenic and metastatic abilities of $\mathrm{ALDH}^{+} \mathrm{CD} 44^{+} \mathrm{CXCR} 4^{+} \mathrm{CD} 24^{+}$cells are at least partially attributable to the HOXB9/TGF $\beta$ signalling.

\section{DISCUSSION}

This study compared the gene expression profiles of orthotopic and ectopic tumours formed by PCa cells in mice. We selected HOXB9 as a candidate factor responsible for the extensive metastases originating from orthotopic tumours. HOXB9 is in the HOX transcription factor family and was overexpressed in many types of tumours [37-40]. Previous studies have shown that HOXB9 overexpression may promote distal metastasis, and is correlated with clinical outcomes in breast, colon, and lung cancers $[25,40,41]$, which links HOXB9's biological function to solid tumour invasion and metastasis. However, the role of HOXB9 in PCa remains unclear. In our study, we confirmed that HOXB9 was abundantly expressed in PCa tissues and that the HOXB9 overexpression was also correlated with increased Gleason scores and poor overall patient survival. This suggests that HOXB9 may be a prognosis biomarker for PCa patients. Our data demonstrated that HOXB9 knockdown mitigated the number of lung metastatic foci in the orthotopic PCa tumour models. Mechanistically, HOXB9 could alter the expression of a panel of CSC growth- and metastasis-related genes, as well as regulate the metastatic behaviour of $\mathrm{ALDH}^{+} \mathrm{CD} 44^{+} \mathrm{CXCR} 4^{+} \mathrm{CD} 24^{+} \quad$-PCa cells, via TGF $\beta$ signalling. Collectively, these findings suggest that HOXB9 is essential for PCa to metastasis.

EMT is a process in which adherent epithelial cells are converted into migratory mesenchymal cells capable of invading the extracellular matrix, which plays a critical role in cancer metastasis [42]. TGF $\beta$ signalling is a classical molecular pathway associated with EMT [43]. It has been found that HOXB9 induces both TGF $\beta 1$ and TGF $\beta 2$ upregulation in normal human mammary epithelial cells. This enhances cell motility and mesenchymal phenotype acquisition [25], suggesting that HOXB9 may induce EMT by activating the TGF $\beta$ signalling. The TGF $\beta$ subfamily members mediate intracellular signalling via the Smad family [44]. Our results showed that the enforced expression of HOXB9 in PCa cells significantly increased TGF $\beta 2$ mRNA and $p$-Smad2 protein levels, while HOXB9 knockdown decreased TGF $\beta 2$ expression. Suppressing TGF $\beta$ receptor signalling with the specific inhibitor SD208 suppressed Smad2 phosphorylation without affecting HOXB9 expression. This suggests that HOXB9 is an upstream activator of TGF $\beta / S m a d 2$ signalling. In addition, the HOXB9induced upregulated expression of SSP1 and MMP9, two wellknown cancer metastasis promoters $[45,46]$, was suppressed by TGF $\beta$ inhibitor. This suggests that SSP1 and MMP9 are downstream target genes of the HOXB9/TGF $\beta / \mathrm{Smad} 2$ pathway in the regulation of cancer metastasis. Thus, we speculate that HOXB9 may activate TGF $\beta / S m a d 2$ signalling, which in turn alters a panel of downstream target genes involved in cancer cell invasion and metastasis.

A previous study found that PCa cells expressing CSC marker CD44 are more tumorigenic and metastatic than isogenic CD44 cells [13]. However, little is known about the underlying regulatory mechanism behind this. In this study, HOXB9 overexpression induced CD44 transcription, whereas HOXB9 knockdown suppressed CD44 protein expression. However, no changes were observed in the expression of HOXB9, TGF 32 or $\mathrm{p}$-Smad2 in response to CD44 knockdown. These data suggest that HOXB9 is an upstream regulator of CD44 and may be responsible for the enhanced metastatic potential of $\mathrm{CD}_{4} 4^{+}-\mathrm{PCa}$ cells. To investigate the promotive role of HOXB9 in PCa metastasis, we isolated homogenous PCa subpopulations carrying different combinations of CSC markers from orthotopic PCa tumours. In the tumour models established with each subpopulation, we found that the combination of CSC markers synergistically reinforced the tumorigenic and metastatic abilities of PCa cells. Thus, they became potential mPCSCs. The preferential expression of the "stemness genes" Nanog, OCT4, Sox2 and FoxD3 [31-34] in the $\mathrm{ALDH}^{+} \mathrm{CD} 44^{+} \mathrm{CXCR} 4^{+} \mathrm{CD} 24^{+}$subpopulation may have endowed these cells with certain stem cell properties. Intriguingly, HOXB9 and TGF $\beta 2$ expression was significantly upregulated in PCa cells carrying different combinations of CSC markers, compared with those in unsorted cells $\left(\mathrm{ALDH}^{+} \mathrm{CD} 44^{+} \mathrm{CXCR} 4^{+} \mathrm{CD} 24^{+}>\right.$ $\mathrm{CD} 44^{+} \mathrm{a} 2 \beta 1^{+}>\mathrm{CD} 44^{+}$in terms of HOXB9 or TGF $\beta 2$ protein levels). This may explain the synergism generated by combining CSC markers in PCa cells. The suppression of the TGF $\beta$ signalling with the inhibitor significantly suppressed the tumorigenic and metastatic abilities of $\mathrm{ALDH}^{+} \mathrm{CD} 44^{+} \mathrm{CXCR} 4^{+} \mathrm{CD} 24^{+}-\mathrm{PCa}$ cells in vivo. This confirmed the importance of HOXB9/TGF $\beta$ signalling in PCa initiation and metastasis. Our results also demonstrated that $\mathrm{ALDH}^{+} \mathrm{CD} 44^{+} \mathrm{CXCR} 4^{+} \mathrm{CD} 24^{+}$cells were castration-resistant and that $\mathrm{ALDH}^{-} \mathrm{CD} 44^{-} \mathrm{CXCR} 4^{-} \mathrm{CD} 24^{-}$cells derived from CWR22 xenograft exhibited phenotypic conversion and EMT in a timedependent manner in the presence of anti-androgens. This is consistent with a recent study [47]. HOXB9 and CSC markers were simultaneously overexpressed in human refractory $\mathrm{PCa}$ tissues, compared with low-grade PCa, para-carcinoma, and initial PCa tissues implying the involvement of HOXB9 signalling's involvement in $\mathrm{ALDH}^{+} \mathrm{CD} 44^{+} \mathrm{CXCR} 4{ }^{+} \mathrm{CD} 24^{+}-\mathrm{PCa}$ cell-rendered castration resistance.

In conclusion, our study demonstrated the promotive role of HOXB9 in PCa tumorigenesis and metastasis through altering the expression of CSC- and metastasis-related genes and enhancing the tumorigenic/metastatic potential of mPCSCs via TGF $\beta$ signalling. HOXB9 overexpression was observed in patients' primary $\mathrm{PCa}$ tissues. It was correlated with high-grade tumours and poor overall survival and involved in $\mathrm{ALDH}^{+} \mathrm{CD} 44^{+} \mathrm{CXCR} 4^{+} \mathrm{CD} 24^{+}$-cellrendered castration resistance. Therefore, HOXB9 may serve as a prognostic biomarker and a potential therapeutic target for refractory PCa treatment.

\section{DATA AVAILABILITY}

All the original data which were available upon request were kept in the database management system within the Center for Medical Research and Innovation, Shanghai Pudong Hospital, Fudan University Pudong Medical Center.

\section{REFERENCES}

1. Ziaee S, Chu GC, Huang JM, Sieh S, Chung LW. Prostate cancer metastasis: roles of recruitment and reprogramming, cell signal network and three-dimensional growth characteristics. Transl Androl Urol. 2015;4:438-54.

2. Hassanipour-Azgomi S, Mohammadian-Hafshejani A, Ghoncheh M, Towhidi F, Jamehshorani S, Salehiniya $\mathrm{H}$. Incidence and mortality of prostate cancer and their relationship with the Human Development Index worldwide. Prostate Int. 2016:4:118-24.

3. DeSantis $C E$, Lin CC, Mariotto $A B$, Siegel RL, Stein KD, Kramer JL, et al. Cancer treatment and survivorship statistics, 2014. CA Cancer J Clin. 2014;64:252-71.

4. Valastyan S, Weinberg RA. Tumor metastasis: molecular insights and evolving paradigms. Cell. 2011;147:275-92.

5. Luzzi KJ, MacDonald IC, Schmidt EE, Kerkvliet N, Morris VL, Chambers AF, et al. Multistep nature of metastatic inefficiency: dormancy of solitary cells after successful extravasation and limited survival of early micrometastases. Am J Pathol. 1998:153:865-73.

6. Liao WT, Ye YP, Deng YJ, Bian XW, Ding YQ. Metastatic cancer stem cells: from the concept to therapeutics. Am. J Stem Cells. 2014;3:46-62. 
7. Korski K, Malicka-Durczak A, Breborowicz J. Expression of stem cell marker CD44 in prostate cancer biopsies predicts cancer grade in radical prostatectomy specimens. Pol J Pathol. 2014;65:291-5.

8. Jaggupilli A, Elkord E. Significance of CD44 and CD24 as cancer stem cell markers: an enduring ambiguity. Clin Dev Immunol. 2012;2012:708036.

9. Yamazaki $H$, Katsumata $K$. Observation of $S=1$ fractional spins in the $S=2$ finite linear-chain Heisenberg antiferromagnet $\mathrm{CsCr}_{1-x M g x C l}$. Phys Rev B Condens Matter. 1996;54:R6831-R6834.

10. Vassalli G. Aldehyde dehydrogenases: not just markers, but functional regulators of stem cells. Stem Cells Int. 2019;2019:3904645.

11. Adorno-Cruz V, Liu H. Regulation and functions of integrin alpha2 in cell adhesion and disease. Genes Dis. 2019;6:16-24.

12. Dubrovska A, Elliott J, Salamone RJ, Telegeev GD, Stakhovsky AE, Schepotin IB, et al. CXCR4 expression in prostate cancer progenitor cells. PLoS ONE. 2012;7: e31226.

13. Patrawala L, Calhoun T, Schneider-Broussard R, Li H, Bhatia B, Tang S, et al. Highly purified $\mathrm{CD} 44^{+}$prostate cancer cells from xenograft human tumors are enriched in tumorigenic and metastatic progenitor cells. Oncogene. 2006;25:1696-708.

14. Lai CJ, Lin CY, Liao WY, Hour TC, Wang HD, Chuu CP. CD44 promotes migration and invasion of docetaxel-resistant prostate cancer cells likely via induction of Hippo-Yap signaling. Cells 2019;8:295.

15. Kristiansen G, Pilarsky C, Pervan J, Sturzebecher B, Stephan C, Jung K, et al. CD24 expression is a significant predictor of PSA relapse and poor prognosis in low grade or organ confined prostate cancer. Prostate. 2004;58:183-92.

16. Reyes EE, Gillard M, Duggan R, Wroblewski K, Kregel S, Isikbay M, et al. Molecular analysis of CD133-positive circulating tumor cells from patients with metastatic castration-resistant prostate cancer. J Transl Sci. 2015;1:1-19.

17. van den Hoogen C, van der Horst G, Cheung H, Buijs JT, Lippitt JM, Guzman-Ramirez N, et al. High aldehyde dehydrogenase activity identifies tumorinitiating and metastasis-initiating cells in human prostate cancer. Cancer Res. 2010;70:5163-73.

18. Sottnik JL, Daignault-Newton S, Zhang X, Morrissey C, Hussain MH, Keller ET, et al. Integrin alpha2beta 1 (alpha2beta1) promotes prostate cancer skeletal metastasis. Clin Exp. Metastasis. 2013;30:569-78.

19. Sun YX, Schneider A, Jung Y, Wang J, Dai J, Wang J, et al. Skeletal localization and neutralization of the SDF-1(CXCL12)/CXCR4 axis blocks prostate cancer metastasis and growth in osseous sites in vivo. J Bone Min Res. 2005;20:318-29.

20. Taichman RS, Cooper C, Keller ET, Pienta KJ, Taichman NS, McCauley LK. Use of the stromal cell-derived factor-1/CXCR4 pathway in prostate cancer metastasis to bone. Cancer Res. 2002;62:1832-7.

21. Hermann PC, Huber SL, Herrler T, Aicher A, Ellwart JW, Guba M, et al. Distinct populations of cancer stem cells determine tumor growth and metastatic activity in human pancreatic cancer. Cell Stem Cell. 2007;1:313-23.

22. Liu H, Patel MR, Prescher JA, Patsialou A, Qian D, Lin J, et al. Cancer stem cells from human breast tumors are involved in spontaneous metastases in orthotopic mouse models. Proc Natl Acad Sci USA. 2010;107:18115-20.

23. Hoffman RM. Patient-derived orthotopic xenografts: better mimic of metastasis than subcutaneous xenografts. Nat Rev Cancer. 2015;15:451-2.

24. Justilien V, Fields AP. Utility and applications of orthotopic models of human nonsmall cell lung cancer (NSCLC) for the evaluation of novel and emerging cancer therapeutics. Curr Protoc Pharm. 2013;62:14 27 11-14 2717.

25. Hayashida T, Takahashi F, Chiba N, Brachtel E, Takahashi M, Godin-Heymann N, et al. HOXB9, a gene overexpressed in breast cancer, promotes tumorigenicity and lung metastasis. Proc Natl Acad Sci USA. 2010;107:1100-5.

26. Nguyen DX, Chiang AC, Zhang XH, Kim JY, Kris MG, Ladanyi M, et al. WNT/TCF signaling through LEF1 and HOXB9 mediates lung adenocarcinoma metastasis. Cell. 2009;138:51-62.

27. Qin J, Liu X, Laffin B, Chen X, Choy G, Jeter CR, et al. The PSA(-/lo) prostate cancer cell population harbors self-renewing long-term tumor-propagating cells that resist castration. Cell Stem Cell. 2012;10:556-69.

28. Gao L, Yang X, Zhang H, Yu M, Long J, Yang T. Inhibition of miR-10a-5p suppresses cholangiocarcinoma cell growth through downregulation of Akt pathway. Onco Targets Ther. 2018;11:6981-94.

29. Eminaga S, Teekakirikul P, Seidman CE, Seidman JG. Detection of cell proliferation markers by immunofluorescence staining and microscopy imaging in paraffinembedded tissue sections. Curr Protoc Mol Biol. 2016;115:14 25 11-14 2514.

30. Baerlocher GM, Vulto I, de Jong G, Lansdorp PM. Flow cytometry and FISH to measure the average length of telomeres (flow FISH). Nat Protoc. 2006;1:2365-76.

31. Gong S, Li Q, Jeter CR, Fan Q, Tang DG, Liu B. Regulation of NANOG in cancer cells. Mol Carcinog. 2015;54:679-87.

32. Zhang ZN, Chung SK, Xu Z, Xu Y. Oct4 maintains the pluripotency of human embryonic stem cells by inactivating p53 through Sirt1-mediated deacetylation. Stem Cells. 2014;32:157-65.

33. Feng R, Wen J. Overview of the roles of Sox 2 in stem cell and development. Biol Chem. 2015;396:883-91.
34. Krishnakumar R, Chen AF, Pantovich MG, Danial M, Parchem RJ, Labosky PA, et al. FOXD3 regulates pluripotent stem cell potential by simultaneously initiating and repressing enhancer activity. Cell Stem Cell. 2016;18:104-17.

35. Palla AR, Piazzolla $D$, Abad $M$, Li $H$, Dominguez $O$, Schonthaler $H B$, et al. Reprogramming activity of NANOGP8, a NANOG family member widely expressed in cancer. Oncogene. 2014;33:2513-9.

36. Huang Y, Liang P, Liu D, Huang J, Songyang Z. Telomere regulation in pluripotent stem cells. Protein Cell. 2014;5:194-202.

37. Shrestha B, Ansari KI, Bhan A, Kasiri S, Hussain I, Mandal SS. Homeodomaincontaining protein HOXB9 regulates expression of growth and angiogenic factors, facilitates tumor growth in vitro and is overexpressed in breast cancer tissue. FEBS J. 2012;279:3715-26.

38. Nagel S, Burek C, Venturini L, Scherr M, Quentmeier H, Meyer C, et al. Comprehensive analysis of homeobox genes in Hodgkin lymphoma cell lines identifies dysregulated expression of HOXB9 mediated via ERK5 signaling and BMI1. Blood. 2007;109:3015-23.

39. Yamagishi T, Hirose $\mathrm{S}$, Kondo T. Secondary DNA structure formation for Hoxb9 promoter and identification of its specific binding protein. Nucleic Acids Res. 2008;36:1965-75.

40. Huang K, Yuan R, Wang K, Hu J, Huang Z, Yan C, et al. Overexpression of HOXB9 promotes metastasis and indicates poor prognosis in colon cancer. Chin J Cancer Res. 2014;26:72-80.

41. Seki $H$, Hayashida $T$, Jinno $H$, Hirose $S$, Sakata $M$, Takahashi $M$, et al. HOXB9 expression promoting tumor cell proliferation and angiogenesis is associated with clinical outcomes in breast cancer patients. Ann Surg Oncol. 2012;19:1831-40.

42. Heerboth S, Housman G, Leary M, Longacre M, Byler S, Lapinska K, et al. EMT and tumor metastasis. Clin Transl Med. 2015;4:6

43. Micalizzi DS, Farabaugh SM, Ford HL. Epithelial-mesenchymal transition in cancer: parallels between normal development and tumor progression. J Mammary Gland Biol Neoplasia. 2010;15:117-34.

44. Samanta D, Datta PK. Alterations in the Smad pathway in human cancers. Front Biosci. 2012;17:1281-93.

45. Xu C, Sun L, Jiang C, Zhou H, Gu L, Liu Y, et al. SPP1, analyzed by bioinformatics methods, promotes the metastasis in colorectal cancer by activating EMT pathway. Biomed Pharmacother. 2017;91:1167-77.

46. Illemann M, Bird N, Majeed A, Sehested M, Laerum OD, Lund LR, et al. MMP-9 is differentially expressed in primary human colorectal adenocarcinomas and their metastases. Mol Cancer Res. 2006;4:293-302.

47. Sun $Y$, Wang BE, Leong KG, Yue $P$, Li L, Jhunjhunwala $S$, et al. Androgen deprivation causes epithelial-mesenchymal transition in the prostate: implications for androgen-deprivation therapy. Cancer Res. 2012;72:527-36.

\section{ACKNOWLEDGEMENTS}

We thank Ms. Ting Cao for qPCR, Histology Core for immunohistochemistry, and other members of the Yang laboratory for constructive discussions and technical assistance. We apologise to the colleagues whose work was not cited due to space constraints.

\section{AUTHOR CONTRIBUTIONS}

TY, YS and WH conceived and coordinated the study; TY, YS, WH, WZ, DL, HZ, QHY, RZ and QTY, designed, performed and analysed the experiments; YS, WH, WZ, DL and TY wrote the paper; YS, WH, WZ, DL, HZ, QHY, RZ, QTY, TT, LG, SZ and TY carried out the data collection and data analysis, and TY revised the paper. All authors reviewed the results and approved the final version of the manuscript.

\section{FUNDING}

The work was financially supported by the National Natural Science Foundation of China (Grant no. 81572518 \& 81372750 to TY, Grant no. 81660150 to YS) and Academic Leaders Training Program of Pudong Health Bureau of Shanghai (Grant no. PWRd2018-07) to TY, and Science and Technology Development Fund of Shanghai Pudong New Area (Grant no. PKJ2020-Y47) to TY, and The Key Basic Applied Project of Hebei Provincial Department of Science \& Technology (grant No. $15967730 D)$ to $W Z$.

\section{ETHICS APPROVAL AND CONSENT TO PARTICIPATE}

This study was approved by the Shanghai Pudong Hospital Ethics Committee, and written informed consent was obtained from the patients involved. Animal care and all experimental procedures were performed in accordance with the Guide for the Care and Use of Laboratory Animals published by the US National Institutes of Health 
(publication No. 85-23, revised 1996). All animal experiments were performed in accordance with the guidelines for the proper conduct of animal experiments, as stipulated by Shanghai Pudong Hospital Ethics Committee.

\section{CONSENT TO PUBLISH}

The manuscript has been seen and approved by all authors.

\section{COMPETING INTERESTS}

The authors declare no competing interests.

\section{ADDITIONAL INFORMATION}

Supplementary information The online version contains supplementary material available at https://doi.org/10.1038/s41416-021-01482-y.

Correspondence and requests for materials should be addressed to T.Y.

Reprints and permission information is available at http://www.nature.com/ reprints
Publisher's note Springer Nature remains neutral with regard to jurisdictional claims in published maps and institutional affiliations. (c) (i) Open Access This article is licensed under a Creative Commons cc) Attribution 4.0 International License, which permits use, sharing, adaptation, distribution and reproduction in any medium or format, as long as you give appropriate credit to the original author(s) and the source, provide a link to the Creative Commons license, and indicate if changes were made. The images or other third party material in this article are included in the article's Creative Commons license, unless indicated otherwise in a credit line to the material. If material is not included in the article's Creative Commons license and your intended use is not permitted by statutory regulation or exceeds the permitted use, you will need to obtain permission directly from the copyright holder. To view a copy of this license, visit http://creativecommons. org/licenses/by/4.0/.

(c) The Author(s) 2021 